\title{
Influence of drift angle on the computation of hull-propeller- rudder interaction
}

\author{
Charles E. Badoe ${ }^{1}$, Alexander B. Phillips ${ }^{1}$, Stephen R. Turnock ${ }^{1}$ \\ Fluid Structure Interactions Research Group, Faculty of Engineering and the Environment \\ University of Southampton, Southampton \\ United Kingdom SO17 1BJ
}

\begin{abstract}
The operation of the propeller dominates the flow interaction effects on the upstream hull and a downstream rudder. An investigation is carried out into the sensitivity with which these effects can be resolved when an angle of drift is applied as well as the length of an upstream body is varied. The computed results are compared to a detailed wind tunnel investigation which measured changes in propeller thrust, torque and rudder forces. Variation of the upstream body length and drift angle effectively varies the magnitude of the crossflow and wake at the propeller plane. The time resolved flow was computed around the hull-propellerrudder configuration using the Reynolds-averaged Navier-Stokes (RANS) equations and an Arbitrary Mesh Interface (AMI) model to account for the motion of the propeller. A mesh sensitivity study quantifies the necessary number of mesh cells to adequately resolve the flow field. Overall, good agreement is found between the experimental and computational results when predicting the change in propulsive efficiency, flow straightening and rudder manoeuvring performance. However, it can be seen that there is a significant computational expense associated with a time resolved propeller interaction and that alternative body force based methods are likely to still be required with the computation of self-propelled ship manoeuvres.
\end{abstract}

Keywords: hull-propeller-rudder interaction; drift angle; maritime CFD; manoeuvring; flow straightening

\section{Introduction}

Accurate determination of rudder forces when a ship is operating at an angle of drift is a necessary condition for the accurate computation of a ship manouevre and its coursekeeping ability. Similarly, the propulsive efficiency effects of drift and rudder angle could be important in determining the overall effectiveness of energy efficiency devices. Rudder forces are strongly influenced by the interaction between the forces and moments generated on the hull and propeller upstream of the rudder. One fundamental criterion in

Email addresses: cb3e09@ soton.ac.uk (Charles E. Badoe), abp@ soton.ac.uk (Alexander B. Phillips), s.r.turnock@ soton.ac.uk ( Stephen R.Turnock)

${ }^{1}$ Corresponding author, postal address: Fluid Structure Interactions Group (Building 28/1021), Faculty of Engineering and the Environment, Highfield Campus, University of Southampton, Southampton, SO17 1BJ, Tel: +44(0)23-8059-5097 
which the rudder forces depends is the effective rudder angle (Molland and Turnock, 1995). When course change is applied using the rudder, the flow of water is no longer aligned with the hull but develops a crossflow across the propeller plane. This will alter the propeller thrust and torque as well as changing the effective direction of the propeller race. The net sideforce due to the propeller will now vary than that during straight ahead conditions resulting in a decrease in effective inflow angle to the rudder. At the same time the propeller and hull upstream of the rudder also straightens the flow leading to a recovery in the effective inflow angle to the rudder. Flow straightening effects therefore play an important role in the accurate determination of rudder forces during ship manoeuvring. A number of studies, including those of Yumuro $(1974,1975,1978)$ have been conducted to examine the effect of drift angle and flow straightening influence of the combined hull and propeller on the rudder. The influence of drift angle on forces and moments as well as trim and sinkage has also been studied for a cargo/container ship (Longo and Stern, 2002). Kijima et al. (1995, 1996a, 1996b) investigated the hydrodynamic forces acting on a hull in oblique flow conditions. Abramowski (2005) studied the forces on the propeller during ship manoeuvring. Yasukawa et al. (1996) presented a methodology of calculating the hydrodynamic forces on a ship moving with constant rudder angle. Phillips (2009) investigated the manoeuvring coefficients of a self-propelled ship at drift by coupling a propeller performance code based on the blade element momentum theory to a Reynolds averaged Navier Stokes flow solver. El Moctar (2001) applied a finite volume method to viscous flow calculations on a ship's hull and presented the hull forces as a function of drift angle. Jurgens (2005) assessed the maneuverability and controllability of fast planning monohulls by comparing the outcome of tests at angles of drift with results from rudder deflection test to determine the flow straightening effect of the hull on rudder.

However, few works have been reported on the flow straightening influence of the propeller independently on the rudder. One such investigation was carried out by Molland and Turnock (1995) who examined the flow straightening influence of the propeller on the effective angle of drift at the stern and how it alters the performance of the rudder. Simonsen (2000) and Phillips et al. (2010) followed on the work by Molland and Turnock (1995) by providing insight into the interaction between the propeller and rudder at straight ahead conditions using CFD methodologies.

This paper aims to replicate numerically the work carried out by Molland and Turnock (1995) by providing detailed insight into the interaction between the propeller and rudder, flow field information, pressure distributions on the rudder surface and the contribution of thrust and torque augment on the propeller blades for:-

- a propeller-rudder combination with and without applied angles of drift.

- centerline boards of different lengths (Fig.1) situated upstream of the propeller-rudder combination at drift to simulate the influence of an upstream centreboard on flow straightening.

It has been argued by Molland and Turnock $(1991,2002)$ that for a propeller upstream of a rudder, a good approach to model the physics involved is to treat the rudder and propeller as a combined unit. The influence of drift angle can then be applied in the form of velocity and flow straightening inputs to the basic isolated model of the rudder propeller combination. By using such approach, data for the rudder and propeller can be applied downstream of a hull, provided the hull wake fraction and hence the appropriate inflow velocity is applied to the rudder-propeller combination. 
The terminology applied to the flow straightening in the present study is illustrated in Fig. 2, where $\delta$ is the rudder angle relative to ship axis, $\beta_{R}$ is the geometric drift angle at the rudder which is larger than the ships drift angle $\beta$ on a turn. For a model test in wind tunnel or towing $\operatorname{tank} \beta_{R}$ is the same as $\beta$.

With no flow straightening due to the propeller, the geometric rudder angle, $\alpha$, is given by:

$$
\alpha=\delta-\beta_{R}
$$

With flow straightening due to the propeller, the effective rudder angle, $\alpha_{E}$, is given by:

$$
\alpha_{E}=\delta-\alpha_{0}=\delta-\gamma \beta_{R}
$$

where $\gamma$ is the flow straightening factor which depends on drift angle and propeller loading, and $\alpha_{0}$ is the incidence for zero lift and can be obtained from basic lift and drag data (Molland and Turnock, 1995).

\section{Case Description}

The cases considered are based on wind tunnel tests performed by Molland and Turnock (1995) at the University of Southampton $3.5 \mathrm{~m} \times 2.5 \mathrm{~m}$ wind tunnel. The experimental set-up comprises of a $1 \mathrm{~m}$ span, 1.5 geometric aspect ratio rudder based on the NACA 0020 aerofoil section (rudder No.2). A representative propeller based on the Wageningen B4.40 series was used. The propeller is four bladed, with a diameter of $0.8 \mathrm{~m}$. The rudder geometry and its arrangement with respect to the propeller are given in Fig. 3 . Dimensions of the different length of centerline boards are also shown in Fig. 1. Simulations were carried out for a constant wind speed of $10 \mathrm{~m} / \mathrm{s}$ and propeller revolutions of 2100,1460 and $800 \mathrm{rpm}$, corresponding to propeller advance coefficients, $\mathrm{J}=0.36,0.51$ and 0.94 respectively, which covers the operating conditions of most vessels. The propeller P/D at $0.7 \mathrm{R}$ is 0.95 and the rudder-propeller separation was fixed at $\mathrm{X} / \mathrm{D}=0.39$. The rudder was mounted on the propeller centerline corresponding to $\mathrm{Y} / \mathrm{D}=0$ with maximum height of the propeller tip coincident with the rudder tip at $1 \mathrm{~m}$.

Five sets of simulations were carried out:-

i. a propeller rudder combination in isolation at straight ahead conditions, that is without the application of drift angle for geometric rudder angles $\alpha=-10.4^{\circ},-0.4^{\circ}$ and $9.6^{\circ}$.

ii. a propeller rudder combination at drift angle of $-7.5^{\circ}$ for geometric rudder angles $\alpha=-$ $10.4^{\circ},-5.4^{\circ},-0.4^{\circ}, 4.6^{\circ}$ and $9.6^{\circ}$. In relation to ship axis the geometric rudder angles will correspond to $\delta=-17.9^{\circ},-12.9^{\circ},-7.9^{\circ},-2.9^{\circ}$ and $2.1^{\circ}$.

iii. a short centerline board with propeller and rudder at drift angle of $-7.5^{\circ}$ for geometric rudder angles $\alpha=-10.4^{\circ},-0.4^{\circ}$ and $9.6^{\circ}$.

iv. a medium centerline board with propeller and rudder at drift angle of $-7.5^{\circ}$ for geometric rudder angles $\alpha=-10.4^{\circ},-0.4^{\circ}$ and $9.6^{\circ}$.

v. a long centerline board with propeller and rudder at drift angle of $-7.5^{\circ}$ for geometric rudder angles $\alpha=-10.4^{\circ},-0.4^{\circ}$ and $9.6^{\circ}$. 
Full details of the geometrical parameters of the propeller, rudder and centerboard and simulation flow conditions are presented in Tables 1 and 2 respectively. It should be noted that the drift angle simulations were carried out in propeller (+Hull) axis but the rudder results are presented in terms of wind tunnel axis (geometric inflow direction).

\section{Numerical Method}

\subsection{Governing Equations}

The flow generated around the propeller rudder and centerboard configurations at drift can be modeled by the unsteady Reynolds averaged Navier-Stokes equations. Within the assumption of an incompressible fluid, the set of equations may be written in the form:-

$$
\begin{gathered}
\frac{\overline{\partial U_{\mathrm{i}}}}{\partial x_{\mathrm{i}}}=0 \\
\frac{\partial \overline{U_{\mathrm{i}}}}{\partial t}+\frac{\partial \overline{U_{\mathrm{i}} U_{\mathrm{j}}}}{\partial x_{\mathrm{j}}}=-\frac{1}{\rho} \frac{\overline{\partial P}}{\partial x_{\mathrm{i}}}+\frac{\partial}{\partial x_{\mathrm{j}}}\left\{v\left(\frac{\partial \overline{U_{\mathrm{i}}}}{\partial x_{\mathrm{j}}}+\frac{\partial \overline{U_{\mathrm{j}}}}{\partial x_{\mathrm{i}}}\right)\right\}-\frac{\partial \overline{u_{\mathrm{i}}^{\prime} u_{\mathrm{j}}^{\prime}}}{\partial x_{\mathrm{j}}}+\overline{f_{\mathrm{i}}}
\end{gathered}
$$

where $x_{i}$ represents the Cartesian coordinates $(\mathrm{X}, \mathrm{Y}, \mathrm{Z})$ and $U_{i}$ are the Cartesian mean velocity components $\left(\overline{U_{x}}, \overline{U_{y}}, \overline{U_{z}}\right.$ ). The Reynolds stress is $\left(\overline{u_{\mathrm{i}}^{\prime} u_{\mathrm{j}}^{\prime}}\right)$ and must be modeled to close the governing equations by employing an appropriate turbulence model. The Shear Stress Transport (SST) k- $\omega$ turbulence model with wall functions was used for turbulence closure. The model was developed by Menter (1994) to effectively blend the robust and accurate formulation of the $\mathrm{k}-\omega$ model in the near-wall region with the free-stream independence of the k- $\varepsilon$ model in the far field. The advantages of using this model are its ability to predict more accurately non-equilibrium regions in boundary layer with adverse pressure gradients, (Gothenburg, 2010). The SST k- $\omega$ model has also been reasonable and credible when applied to the calculations of hydrodynamic forces of ship drift motion, (Yunming et al., 2010; Phillips, 2009).

\subsection{Applied RANS-CFD solver}

Numerical solution of the above equations is carried out using the open source Reynolds- averaged Navier-Stokes (RANS) solver OpenFOAM, which is primarily designed to solve problems in mechanics of continuous mediums; see Jasak (1996) for more details on introduction and numeric used in OpenFOAM. The unsteady RANS equations were solved using a cell centered finite volume method (FVM). Discretization of the convection terms were achieved using a Gauss linear second order upwind scheme. The diffusion terms utilized the central difference scheme. The pimpleDyMFoam solver in OpenFOAM, which is a transient solver for incompressible flow on a moving mesh utilizing the PIMPLE (merged PISO-SIMPLE) algorithm, was used. The PIMPLE algorithm includes both under relaxation and velocity correction and is mainly used for transient flows but without courant number 
constraints of the PISO algorithm. Three outer loops, each with one inner pressure loop, were run until the residuals converged to at least $1 \mathrm{e}-8$ at each time step. The rotating propeller was accounted for using a sliding grid provided by the arbitrary mesh interface (AMI) for nonconformal mesh regions. This technique allows flow data to be exchanged across disconnected mesh domains which can either be stationary or moving relative to one another. The algorithm is described by Farrell and Maddison, (2011). In the discussed context, it operates by projecting one of the sides of the interface on to the other and is used for handling rotating meshes. The AMI concept is based on a set of weighting factors that balance fluxes at the region interface. The straight ahead or no drift angle cases were started from rest and run for approximately 25 propeller revolutions whilst that of the drift angle cases were run for about 40 propeller revolutions due to the different flow patterns.

\subsection{Domain and Boundary conditions}

The entire flow field was considered as a result of asymmetry of the flow induced by the oblique motion and rotation induced by the propeller. Due to the complexity of the arbitrary mesh interface technique (AMI) in handling propeller models at an angle, propeller drift angle was achieved by keeping the propeller fixed and rotating the wind tunnel and inflow as per the required drift angle as illustrated in Fig. 4. This technique was automated by employing a script which, when called upon, allows rotation of the tunnel and inflow to the required propeller drift. For the straight ahead case the wind tunnel and inflow were not rotated. The inflow and outflow plane were located 8 rudder chord lengths upstream of the rudder leading edge and 12 rudder chord lengths downstream of the rudder trailing edge respectively. The domain size represents the wind tunnel dimensions. The origin of the coordinates is defined at $0.3 \mathrm{c}$ from the leading edge at geometric angle of attack $\alpha=0^{\circ}$, the $\mathrm{x}$ axis pointing downstream along the wind tunnel symmetry line. The nominal inflow velocity of $10 \mathrm{~m} / \mathrm{s}$, turbulence intensity 0.04 and eddy length scale of $0.27 \mathrm{~m}$ are set at the inlet. At the outlet boundary a zero gradient was applied. The centerboard, propeller and rudder assumed a no slip boundary condition. Slip boundary condition was applied to the wind tunnel floor, walls and ceiling. As a result of the cost involved in computation it was not possible to mirror all geometric aspect of the experiments; as such the geometry was simplified. The gap between the rudder and wind tunnel floor was neglected, as was the support structure for the propeller. Table 3 summarizes the computational parameters adopted for this study as well as identifying typical run times.

\section{Grid Generation}

All grids were created utilizing both blockMesh and snappyHexMesh in OpenFOAM version 2.1.0. Firstly an initial structured hexahedral background mesh consisting of a multiblock topology structure was generated using blockMesh with nine blocks as shown in Fig. 4. The centre block encompasses all the propeller, rudder and centerboard geometries, with initial grid node distribution of around $n_{\xi}=80, n_{\eta}=18$, and in the wake $n_{\zeta}=36$ of the rudder section making a total of about $50 \mathrm{~K}$ cells (for the coarse grid). An unstructured, predominantly hexahedral mesh with local refinements around no slip walls was then created 
using snappyHexMesh utility. The snappyHexMesh approximately conforms to the geometries by iteratively refining the blockMesh and morphing the resulting split-hex mesh to the geometries. Specific areas within the domain were then specified for mesh refinement in progressive layers. For each layer of refinement each cell is split into eight equal parts, doubling the mesh density in all directions. Apart from the mid-block fitted around the geometries, most of the remaining cells were placed in the downstream block to capture both the propeller race and the rudder wake (Fig. 5a). Since the propeller was close to the rudder extra care was taken with the AMI patches to allow smooth rotation without conflicting with the rudder grids and also keeping in mind the associated computational cost. For the propeller mesh, the complexity of the propeller especially around the blade tip with very small thickness and the difficulties associated with the use of snappyHexMesh in generating boundary layers on geometries with sharp corners and complex curvatures made it possible to place only two prism layer on the propeller. The surface refinement for the propeller was increased to ensure that most of the flow features were resolved. The average $\mathrm{y}^{+}$on the propeller was between 60-100. Ten elements were used to capture the boundary layer of the rudder with average $\mathrm{y}^{+}$of 30 .

\subsection{Grid sensitivity studies}

A grid sensitivity study was conducted to provide insight into the impact of grid spacing on the overall performance prediction of the propeller and rudder at straight ahead conditions, that is drift angle, $\beta_{R}=0^{\circ}$, propeller advance ratio, $\mathrm{J}=0.36$ and geometric rudder angle $\alpha=10^{\circ}$. The methodology used was based on that presented by Stern et al. (1999). While this is applicable to structured mesh, it was assumed to be a suitable approach when using unstructured meshing strategy. In the present study of the grid, the contributions to the numerical uncertainty and error originating from iterations were not investigated, only the uncertainty introduced by the grids were investigated. Three grids referred to as coarse, medium and fine were generated based on the same geometry definition by a systematic $\sqrt{2}$ refinement of the background structured blockMesh. The number of points in all three directions of longitudinal, lateral and spanwise was varied. The grid system used for the sensitivity analysis is shown in Table 4 . The total number of cells in the coarse, medium and fine grids was $1.4 \times 10^{6}, 3.3 \times 10^{6}$ and $8.8 \times 10^{6}$ respectively.

Illustrations of the grids generated on the propeller are shown in Fig. 5 for (b) coarse, (c) medium and (d) fine grid. Detailed grid parameters are also summarized in Tables 5 and 6 , along with the comparison of predicted thrust and torque computed on each grid as well as viscous and pressure contributions to the total drag. Rudder lift and drag values are also presented for Simonsen (2000) and Philips et al., (2010) who both performed similar investigations for straight ahead conditions (no applied angle of drift) using the CFDSHIPIOWA and ANSYS CFX code respectively and using a body force propeller model with load distribution based on the Hough and Ordway, (1965) thrust and torque distribution. By considering the $R_{G}$ values, it can be observed that the rudder drag exhibited the diverging condition; hence uncertainty analysis was not estimated. The grid could have been improved especially around the tip region, hub, the leading edge of the rudder and root. According to Simonsen, (2000) since the X-component of the normal to the rudder surface is large at the leading edge, the pressure contribution is dominant for the local drag coefficient in this region, therefore if the leading edge pressure and suction peaks are not adequately resolved it could lead to discrepancies in drag coefficient. The grid quality was not improved further due to expense involved in computation (see Table 4). Although the detail local flow features 
such as the tip and hub vortices (which are useful for cavitation analysis) described above will not be captured by the level of grid used, for manoeuvring performance of the rudder exact "mirroring" of the flow field is not essential as long as the required condition of flow (head) are adequately captured. Another problem regarding the drag coefficient values might be attributed to insufficient turbulence model which may have influenced the frictional drag values. The numerical simulation assumed a fully turbulent boundary layer, while the flow over the experimental rudder was tripped from laminar to turbulent flow at a distance of $5.7 \%$ from the leading edge of the chord on both sides of the rudder using turbulence strips. This problem has been addressed by Wang and Walters (2012) who carried out studies to demonstrate the capability of transition sensitive turbulence models for three dimension turbulent flows around complex geometries to determine the relative importance of resolving the boundary layer transitional effect. According to Wang and Walters (2012) the SST is poorer at resolving the tip vortices and showed large discrepancies in propeller forces with increased propeller loads compared to transition sensitive models and this will have a significant effect on the forces of a rudder placed downstream of the propeller. It should also be noted however that assumptions were made by neglecting the gap between the rudder and the wind tunnel floor and also the support structure for the propeller which probably have effects on the drag force of the rudder.

The $R_{G}$ values for the other entire parameters aside the rudder drag exhibited the converging condition. This means that all parameters except rudder drag were converging as the grids were refined. Uncertainty estimates were then made since the correction factor $\left(C_{G}\right)$ of the propeller thrust coefficient, torque coefficient and rudder lift force were less than 1 (see Table 6). The uncertainty $U_{G}$ introduced by using the fine grid was $7 \%, 21 \%$ and $29 \%$ of the numerical benchmark, $S_{C}$ for the propeller thrust coefficient, torque coefficient and rudder lift force respectively. Investigations by Simonsen and Stern, (2005) and Phillips et al., (2009) highlight the difficulties in the prediction of propeller torque and rudder forces with large uncertainties and comparison errors between calculated and experimental result unless significantly larger meshes are used. Wang and Walters (2012) indicated values in excess of $22 \mathrm{M}$ to resolve propeller forces, whilst Date and Turnock (2002) indicates values of 5-20M cells to fully resolve the ruder forces. However, a good level of understanding of the global forces required for rudder and propeller forces during manoeuvring may be obtained with this level of mesh resolution.

The time history for rudder and propeller forces for the medium grid presented in Fig 6 shows that the all the forces have converged at about $0.2 \mathrm{secs}$, this correspond to approximately 8 propeller revolutions. However as stated earlier the simulation was run a little longer for about 25 propeller revolutions to obtain a fully converged solution.

Aside from the overall thrust and torque, the rudder lift and drag coefficient for geometric rudder angles $\alpha=-10^{\circ}, 0^{\circ}$, and $10^{\circ}$ are shown in Fig. 7. Comparison is also made with Simonsen (2000) and Phillips (2010). Results show improvement in the fine grid especially for drag coefficient. The calculated drag however is still greater than the experiment. This is due to the difficulties associated with replicating the influence of swirl on the local incidence angle. At high thrust loadings, swirl components increases, leading to a reduction in the drag experienced by the rudder, the mechanism is illustrated in Fig. 8. Other reasons for the drag over prediction have been discussed such as grid resolution and turbulence model. Wall effects also plays a defining role in rudder drag prediction as has been addressed by Höerner (1965) who showed that due to root vortex the drag of wall mounted experimental rudder differs from that of numerical rudder. Because the propeller was working close to the wind tunnel floor, it could have influence the root flow, hence the root vortex and rudder drag prediction. 
The medium grid was used for most aspect of this work unless otherwise stated. This is because of the high computational cost associated with using the fine grid (see Table 4). The medium grid results also compares well with the fine grid in terms of the rudder lift and propeller forces.

\section{Results}

\subsection{Propeller open-water prediction}

Fig. 9 presents the computed open-water performance of the model propeller at drift angles of $0^{\circ}$ and $-7.5^{\circ}$ with corresponding experimental data (for $\beta_{R}=0^{\circ}$ ) provided by Molland and Turnock, (1990). The thrust and torque coefficient can be defined as:

$$
\begin{aligned}
& K_{T}=\frac{T}{\rho n^{2} D^{4}} \\
& K_{Q}=\frac{Q}{\rho n^{2} D^{5}}
\end{aligned}
$$

where $\mathrm{T}$ and $\mathrm{Q}$ are the calculated thrust (force imparted by the fluid on the propeller blades in propellers axial direction) and torque (moment about the centerline of propeller) respectively, $\rho$ is the density of air.

The propeller open-water efficiency is defined as:

where $\mathbf{J}$ is the propeller advance coefficient

$$
\eta_{o}=\frac{J}{2 \pi} \frac{K_{T}}{K_{Q}}
$$

For most of the propeller advance coefficients, the agreement for the propeller forces and efficiencies with experiment was good. For example at $\mathrm{J}$ of 0.36 and 0.51 at $\beta_{R}=0^{\circ}$, the agreement for $K_{T}, 10 K_{Q}$, and $\eta$ was less than $5 \%$. The trends with varying advance coefficients were also well predicted. The data for applied angle of drift $\left(\beta_{R}=-7.5^{\circ}\right)$ also follows the same trend as that of the zero angle of drift but with an upwards shift in propeller thrust and torque coefficient curves.

\subsection{Rudder-propeller combination in isolation}

The global forces for rudder and propeller in isolation, with and without applied drift angle are illustrated in Fig. 10. For non-zero angles of drift, the rudder forces are calculated relative to ship body axis, not the wind tunnel centerline. The lift and drag coefficients are defined normal and parallel to the ship body axis respectively. Results for zero drift angle condition demonstrates that the wake field generated by the propeller compares well with experimental values of lift and drag on a rudder placed aft of the propeller at different angles of incidence. The influence of drift angle is well captured in terms of rudder lift and drag characteristics. The effect of the applied drift angle on the rudder results in a downward shift of the lift curve and does not significantly change the lift curve slope as seen in Fig. 10. 
The applied drift angle also resulted in an over prediction of propeller torque (see Table 7), since rudder forces are dependent on the inflow conditions (propeller race) which in turn are dominated by the action of the propeller, slight over-prediction in propeller force will result in an increased inflow velocity to the rudder, causing an increase in rudder force, hence the upward shift in rudder lift curve observed for the -7.5deg drift angle as compared with experiment. At $\alpha=-10^{\circ}\left(\alpha_{E}\right.$ of $\left.-23^{\circ}\right)$, the predicted accuracy for rudder drag deteriorates. The reason is most likely that the rudder has stalled and the mesh count (of 3.3M) used to mirror entire flow field makes it difficult to capture the stall effect. The grid used, however is able to predict accurately the effective angle of attack $\left(\alpha_{E}\right)$ up to $18^{\circ}\left(\alpha=-5^{\circ}\right)$. Also loss of lift can be observed at rudder angles between $-30^{\circ}$ and $-20^{\circ}$. The influence of advance ratio on the performance of the rudder and propeller at drift is also well captured (Fig. 11). As propeller thrust loading increases the drag experienced by the rudder increases. From the lift curve plots it can be observed that a particular geometric rudder angle exist $\left(4^{\circ}<\alpha<5^{\circ}\right)$ where changes in propeller advance ratio does not have effect on the lift experienced by the rudder. Figure 12 presents the axial velocity contours at three positions along the rudder at midchord, trailing edge and in the wake for the drift angle condition. It is interesting to note how the accelerated flow impinges on the rudder and the development of the tip vortices. At $x=1.05$ chords, the propeller swirl dominates the flow, the rudder wake has mixed with the surrounding faster moving fluid.

The overall results provide reasonable initial estimates for rudder forces at drift angle $\beta_{R}=-7.5^{\circ}$ and $0^{\circ}$. Overall improvements in mesh resolution around the propeller, rudder and rudder tip vortices would improve the quality of the results.

\subsection{Rudder-propeller with different length of upstream boards}

An upstream board or hull at angle of drift slows down the inflow to the propeller. For a rudder downstream of the propeller at drift, accurate determination of the rudder forces is influenced by the axial and tangential wake flow. The investigated flow straightening effect in the presence of three upstream boards as shown in Fig. 13 follows the same trend as that of the rudder-propeller in isolation discussed earlier. In all quantities, i.e. lift and drag characteristics, the calculations compared well with the measured values. The lift curve slope, $\partial C_{L} / \partial \alpha$ (see Table 8) are also well predicted. It can be seen that the presence of the boards tends to reduce the lift curve slope as a result of flow straightening and there is a downward shift in the lift curve compared to the rudder and propeller alone at drift. The calculated drag when approaching stall was not accurately predicted due to similar reasons outlined earlier.

The rudder drag at zero incidence $C_{D_{O}}$ is highest for the rudder-propeller in isolation. Comparison of the plots to that of the non-zero drift angle case in Fig. 10 shows that the asymmetry in the flow results in a shift in the performance of the rudder which increases with increasing upstream board length. This shift may depend on the angle of drift. The lift curves in Fig. 13 also show that, most of the flow straightening was achieved by the short board. Further lengthening of the boards resulted in little flow straightening. This is also shown in a combined plot which clearly illustrates flow straightening effects for all cases considered, Fig. 14. From the plots, the propeller straightened the flow (i.e. $\beta_{R}-\alpha_{0}$ ) by almost $13^{\circ}$ for the short board compared to experimental value of $12^{\circ}$, leading to a significant increase in sideforce. The trend in flow straightening however was not accurately predicted from no-board to the short board. This was expected due to the over-prediction in propeller forces explained earlier (in section 5.2) resulting in an upward shift in rudder lift curve for the 
rudder and propeller alone at drift. Differences in flow straightening (decrease in $\alpha_{o}$ ) predicted from the short-medium board and medium-to long board was both 0.8 for the experiment compared to 0.9 for the calculations.

\subsection{Drift angle influence on propeller performance}

The action of a propeller accelerates the incoming flow onto a downstream rudder thus modifying the flow around the rudder. The rudder itself blocks and diverts the upstream flow onto and through the propeller, affecting the thrust produced and torque developed on the propeller. The influence of the rudder on the propeller thrust performance at drift and with different centerline board lengths (Fig. 15) was investigated by comparing the differences in the net thrust of the propeller and rudder combination and with different centerline boards with the open water data for the propeller at $J=0.36, \beta_{R}=0^{\circ}$ (Fig. 9). The presence of the boards clearly has a marked change on the propeller thrust with the " $d k t$ " curve highest for the medium board. The results show a good $d k t$ prediction for the short and long boards compared with the experiment. At positive geometric rudder angle, the propeller thrust of the medium board was predicted to be the same as the longboard.

\subsection{Comparison of propeller side forces with and without applied angle of drift}

The net sideforce due to the propeller at drift is important in the prediction of a ship manoeuvre. The propeller sideforce results from the rotational motion of the ship and is dependent on the inflow and angle of drift. Fig. 16 presents the sideforce due to the propeller normalized with rudder lift force at an angle of drift of $-7.5^{\circ}$. The sideforce (magnitude in this case) is the resultant of the fluid force component in the propeller plane and is defined as:

$$
K_{s}=\frac{\sqrt{F_{y}^{2}+F_{z}^{2}}}{\rho n^{2} D^{4}}
$$

The results show that the sideforce increases with increasing rudder angle. At $10^{\circ}$ rudder angle the presence of the shortboard increased the propeller sideforce compared to the medium and longboard. This is confirmed in the flow straightening plots in Fig. 14 where the maximum flow straightening was achieved by the shortboard. Comparison of the propeller advance ratios at $10^{\circ}$ rudder angle (Fig. 17) shows that as propeller thrust load increases the sideforce due to the propeller reduces. Values in Fig. 18 of the propeller sideforces without application of drift compared to that at drift (Fig. 17) shows the importance of the propeller sideforce when considering manoeuvrabiity of ships.

\subsection{Data for ship manoeuvring rudder force prediction}

An overall table showing values of propeller sideforces, lift, drag and wake data's for all the cases considered is presented in Table 9. The effective wake fraction was obtained on the basis of thrust identity method. The results in Table 9 may provide initial estimates for straight forward rudder force prediction including effects of drift angle and upstream hull geometry, which is useful in ship manoeuvring rudder force prediction methods.

\subsection{Wake plots}


A wake plot was carried out (in wind tunnel axis) to observe the distribution of velocities arriving at the rudder. The results of such plots are shown in Figs 19-21 for zero and ten degrees rudder angle. Fig 22 presents the location of the wake plots. Differences in the velocity plots were observed for the propeller tangential velocities (v/U plots) in areas of the rudder below the propeller hub, increasing with increase in geometric rudder angle. At $10^{\circ}$ geometric rudder angle, the presence of the boards also increased these velocities. The horizontal velocity plots in Fig 21 showed little difference in all the cases considered. In summary, the plots shows the importance of the tangential velocities for a propeller at drift and these need to be adequately captured to effectively predict the forces on a downstream rudder

\subsection{Rudder pressure distribution}

The chordwise pressure distribution of surface pressures for eight spanwise rudder locations from the root to tip with and without applied angle of drift and for different board lengths are compared in Fig 23. Drift angle influence can be observed for most areas of the rudder span below the center of the slipstream (below the hub).This was also observed in the velocity plots in Figs 19-21 where the tangential velocities of the propeller were dominant in areas below the rudder hub. Close to the slipstream, (span 230 \& 390mm) local incidence resulted in the pressure peak increasing with increasing board lengths at the rudder leading edge. An area of interest was just around the hub where the unsteadiness in the flow introduced by the hub vortex can be observed for span 530 $\mathrm{mm}$ as a bulge in the pressure curve for the zero drift angle around the rudder trailing edge. This was not observed for the drift cases. In areas close to the tip (span $705 \mathrm{~mm}-970 \mathrm{~mm}$ ) there were little or no differences in pressure curves for the drift cases.

\section{Conclusions}

A methodology of gaining valuable insight into the flow straightening influence of the propeller on the effective angle of drift at the stern using an open source CFD code has been presented. Computational results for both global and local flow quantities were discussed and compared well with measured values. The results demonstrate the importance of the effective angle of drift and the sideforce due to the propeller on the performance of the rudder propeller combination. When rudders are placed behind a propeller, lift force increases with increasing propeller load. Effect of drift tends to shift the forces associated with the rudder but does not change them totally. This shift is dependent on the angle of drift. The highest flow straightening occurred due to the presence of the short board. Although the cost in computation to mirror the exact flow field is relatively high, the mesh resolution used provided a good understanding of the complex flow field involved.

To conclude and to relate this investigation to the manoeuvring effectiveness of a rudder, since the lift curve slope was predicted within 2-3\% accuracy the methodology used can be considered acceptable and the results can contribute to improving the reliability of manoeuvring rudder force prediction methods. However, important factors such as a thorough verification and validation, improvements in grid resolution to accurately predict the propeller flow field hence accurate prediction of the rudder forces during stall may be conducted in the future. 


\section{Acknowledgement}

The author acknowledges the use of the IRIDIS High Performance Computing Facility, and associated support services at the University of Southampton in completion of this work. 


\section{References}

Abramowski, T., 2005. Prediction of propeller forces during ship manoeuvring. Journal of theoretical and applied mechanics, 43(1), pp.157-178.

Date, J.C and Turnock, S.R., 2002. Computational evaluation of the periodic performance of a NACA 0012 fitted with a Gurney flap. Journal of Fluids Engineering 124, 227-234.

El Moctar, O.M., 2001. Numerical computations of flow forces in ship manoeuvring. Ship Technology Research, 48, pp.98-123.

Farrell, P.E and Maddison, J.R., 2011. Conservative interpolation between volume meshes by local Galerkin projection. Applied Mechanical Engineering, pp.200-289.

Höerner, S.F., 1965. Fluid -dynamic drag: Practical information on aerodynamic and hydrodynamic resistance.

Hough, G., and Ordway, D., 1964. The Generalized Actuator Disk. Technical Report TARTR 6401, Therm Advanced Research, Inc.

Jasak, H., 1996. Error analysis and estimation for the finite volume method with applications to fluid flows. Ph.D. Thesis, Imperial College of Science, Technology and Medicine, University of London.

Jurgens, A.J., 2005. Static and dynamic effects of rudder-hull-propeller on fact monohulls. In 8th international Conference on Fast sea transport.

Kijima, K., Yukawa, K and Maekawa, K., 1995. An Estimation of hydrodynamic forces acting on a ship hull in oblique motion (in Japanese). Transaction of the West-Japan Society of Naval Architects, 90, pp.115-125.

Kijima, K., Yukawa, K and Maekawa, K., 1996a. An estimation of hydrodynamic forces acting on a ship hull in oblique motion (continued), (in Japanese). Transaction of the West-Japan Society of Naval Architects, 91, pp.95-106.

Kijima, K., Yukawa, K and Maekawa, K., 1996b. An estimation of hydrodynamic forces acting on a ship hull in turning motion (in Japanese). Transaction of the West-Japan Society of Naval Architects, 92, pp.105-116.

Longo, J and Stern, F., 2002. Effect of drift angle on model ship flow. Experiments in Fluids, 32 , pp.558-569.

Menter, F.R., 1994. Two-equation eddy viscosity turbulence models for engineering applications. AIAA journal, 32(8), pp.1598-605.

Molland, A.F and Turnock, S.R., 1991. Wind tunnel investigation of propeller loadings on ships rudder performance. Technical report, University of Southampton Ship Science Report No. 46. 
Molland, A.F and Turnock, S.R., 1995. Wind tunnel test on the effect of a ship hull on rudder-propeller performance at different drift angles. Technical report, University of Southampton Ship Science Report No. 76.

Molland, A.F. and Turnock, S.R., 1996. A compact computational method for predicting forces on a rudder in a propeller slipstream. Transactions of the Royal Institution of Naval Architects, 138, pp.227-244.

Molland, A.F and Turnock, S.R., 2002. Flowstraightening effects on a ship rudder due to upstream propeller and hull. In International Shipbuilding Progress. pp. 195-214.

Molland, A.F and Turnock, S.R., 2007. Marine rudders and control surfaces: principles, data, design and applications, Oxford, UK, Butterworth-Heinemann.

Molland, A.F and Turnock, S.R., 2010. Energy efficiency of ship propulsive systems: rudderpropeller interaction. Ship Propulsion Systems Conference, p.2.

Phillips, A.B., Turnock, S.R., and Furlong, M.E., 2009. Evaluation of manoeuvring coefficients of a self-propelled ship using a blade element momentum propeller model coupled to a Reynolds averaged Navier Stokes flow solver. Ocean Engineering, 36(1516), pp.1217-1225.

Phillips, A.B., Turnock, S.R and Furlong, M.E., 2010. Accurate capture of rudder-propeller interaction using a coupled blade element momentum-RANS approach. Ship Technology Research, 57(2), pp.128-139.

Simonsen, C., 2000. Propeller - rudder interaction by RANS. PhD thesis, Department of Naval Architecture and Offshore Engineering, University of Denmark.

Simonsen, C and Stern, F., 2005. RANS manoeuvring simulation of Esso Osaka with rudder and body-force propeller. Journal of Ship Research, 49(2), pp.98-120.

Stern, F., Wilson, R.V., Coleman, H.W. and Paterson, E.G., 1999. Verification and Validation of CFD simulations. Technical Report IIHR Report No. 407, Iowa Institute of Hydraulic Research.

Wang, X. and Walters, K., 2012. Computational Analysis of Marine-Propeller Performance Using Transition-Sensitive Turbulence Modelling. Journal of Fluids Engineering, 134(7), pp.071107.

Yasukawa, H., Yoshimura, Y. and Nakatake, K., 1996. Hydrodynamic forces on a ship with constant rudder angle: a theoretical treatment of rudder angle test. In International Conference on Marine Simulation and Ship Manoeuvrability. pp. 435-447.

Yumuro, A., 1974. An experimental studies on incoming flow-direction to the rudder of a ship sailing obliquely on rudder performance. Ishikawajima-Harima Engineering Review, 3(4).

Yumuro, A., 1975. A model experiment on incoming flow-direction to the rudder of a ship sailing obliquely. In 14th International Towing Tank Conference. Ottawa, Canada. 
Yumuro, A., 1978. An experimental studies on inflow direction and inflow velocity to the rudder of a ship in manoeuvring motion. In Report for Conference on Ship Manoeuvring and Handling. Bulgaria.

Yunming, Q.Y.Q., Zuyuan, L., Xide, C. and Chengsheng, Z., 2010. Numerical calculation of manoeuvring hydrodynamic forces of drift ship based on SST k-w turbulence model. In 2nd International Conference on Computer Engineering and Technology (ICCET), 1618 April. 

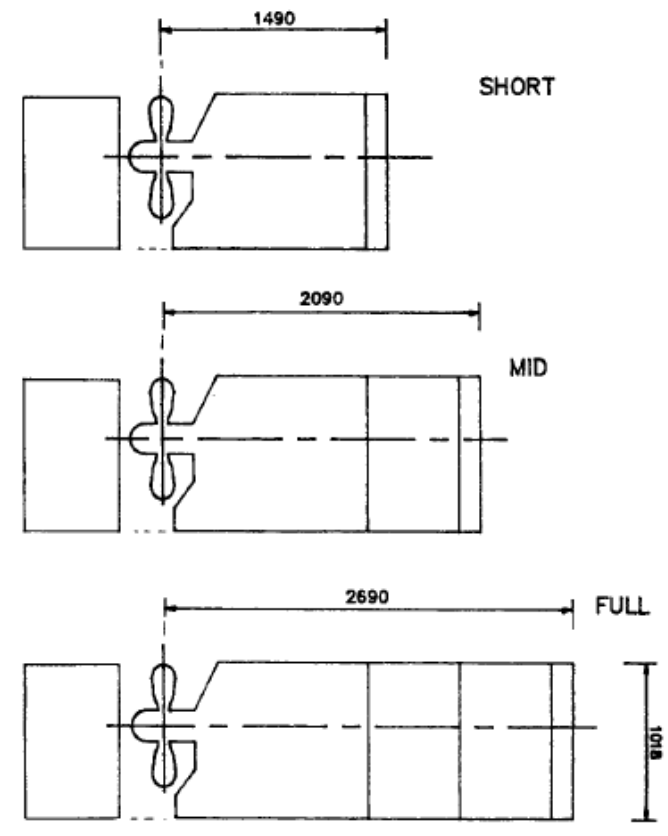

Fig. 1. Overall dimensions of three centerboard configurations, source: Molland and Turnock, (2007).

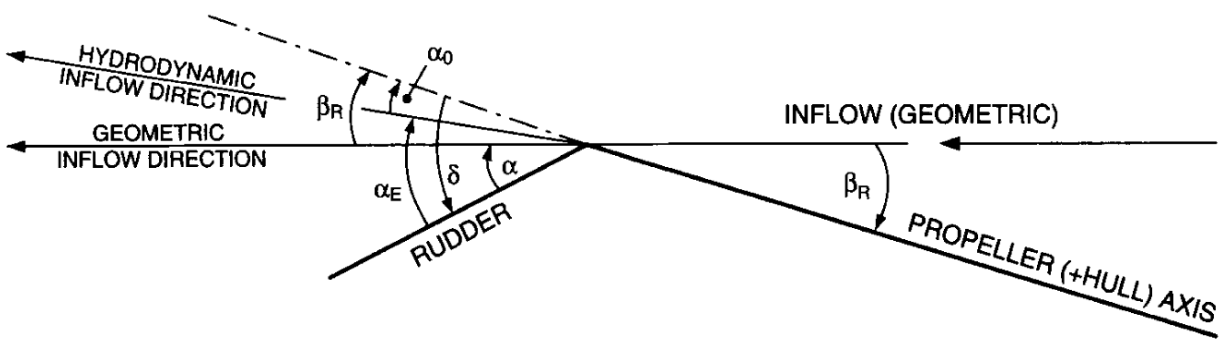

Fig. 2. Flow straightening terminology adapted from, Molland and Turnock, (1995). 


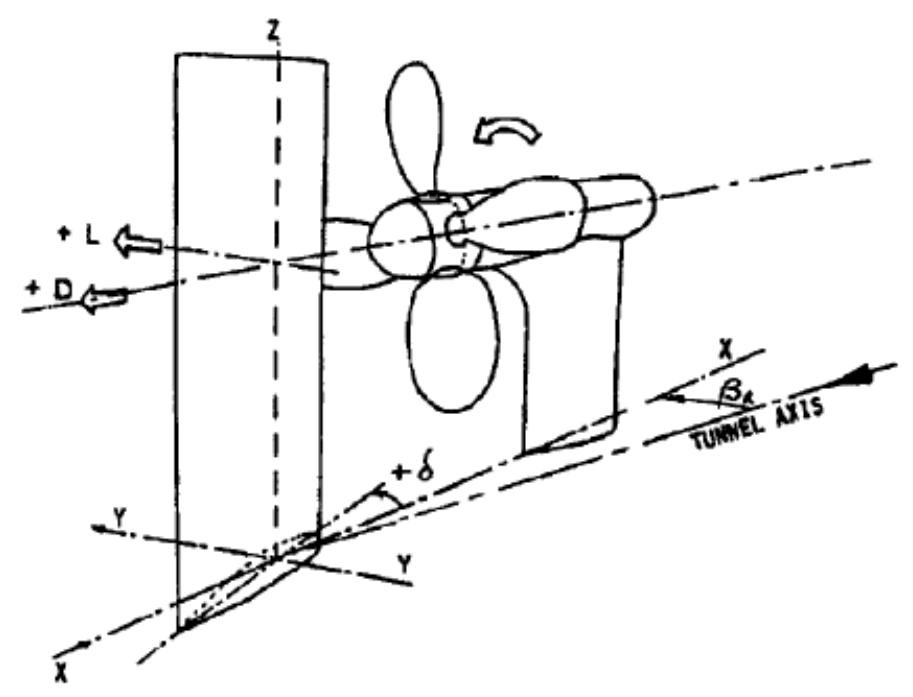

Fig. 3. Rudder geometry and its arrangement in respect to propeller, source: Molland and Turnock, (2007).

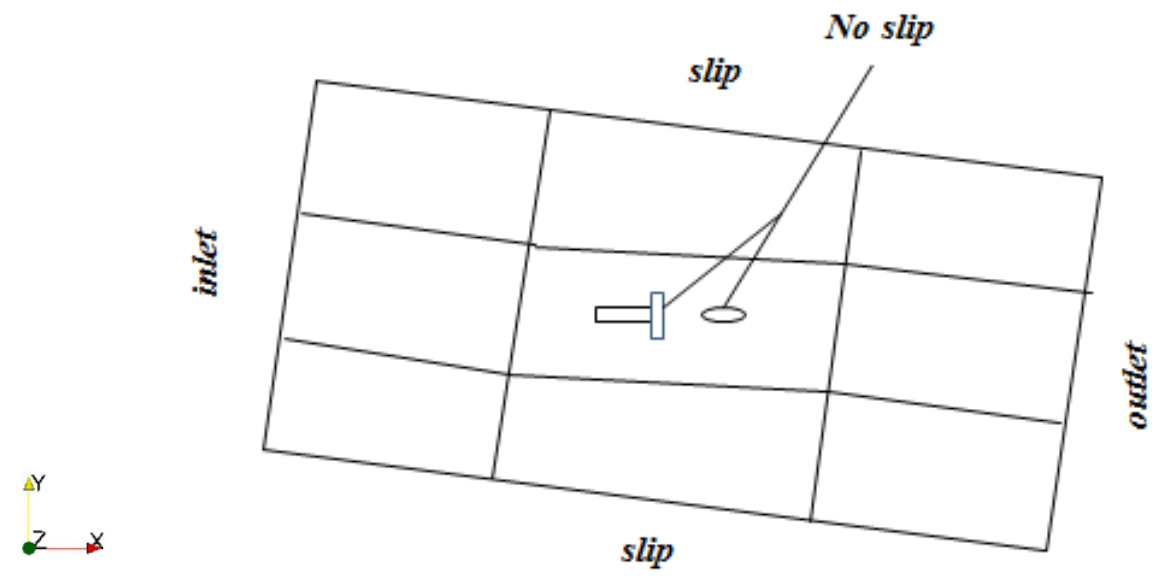

Fig. 4. Applied boundary conditions and co-ordinate system for the drift angle computations. 


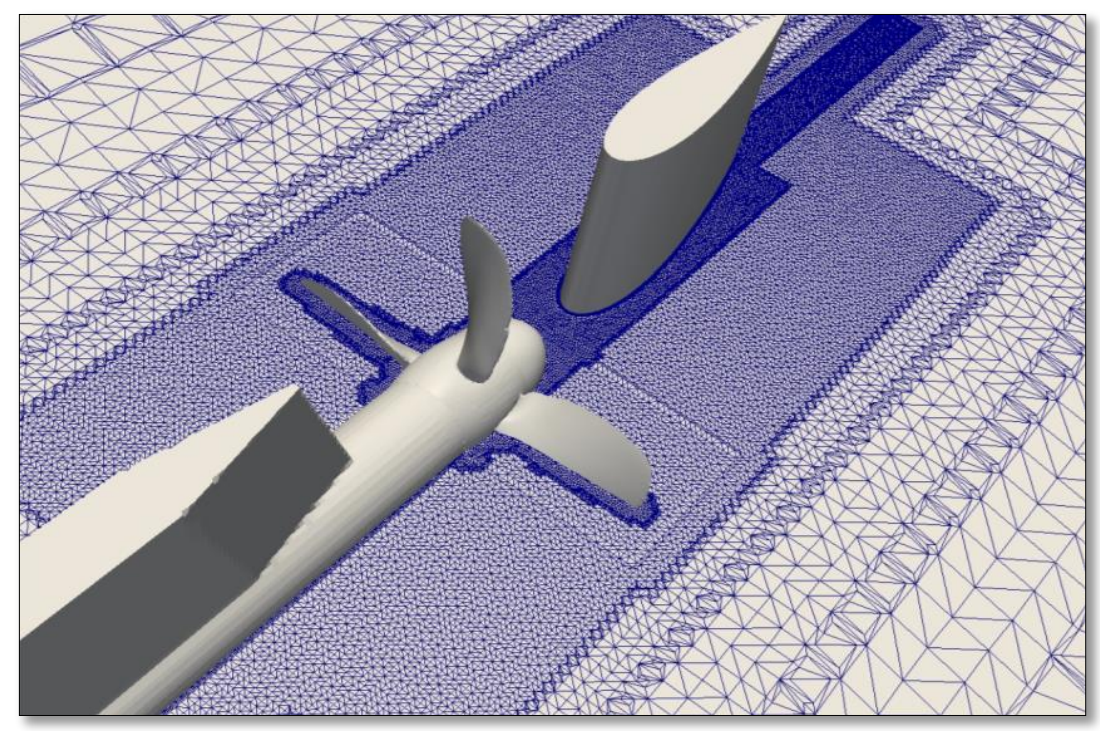

[a]

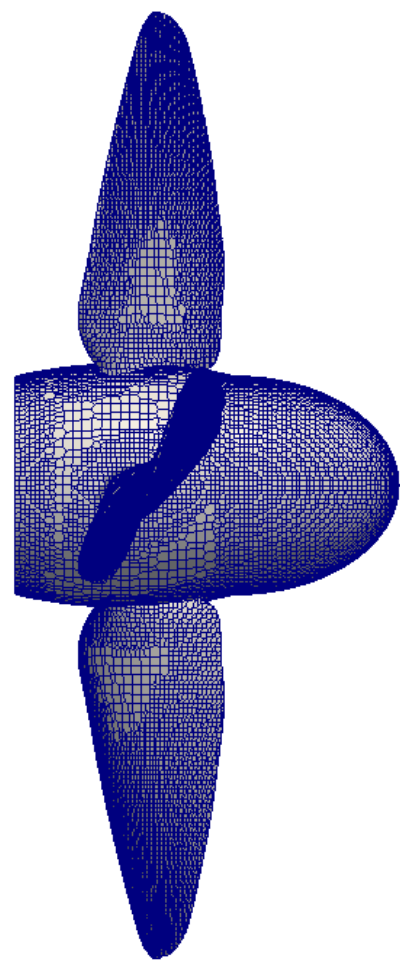

[b]

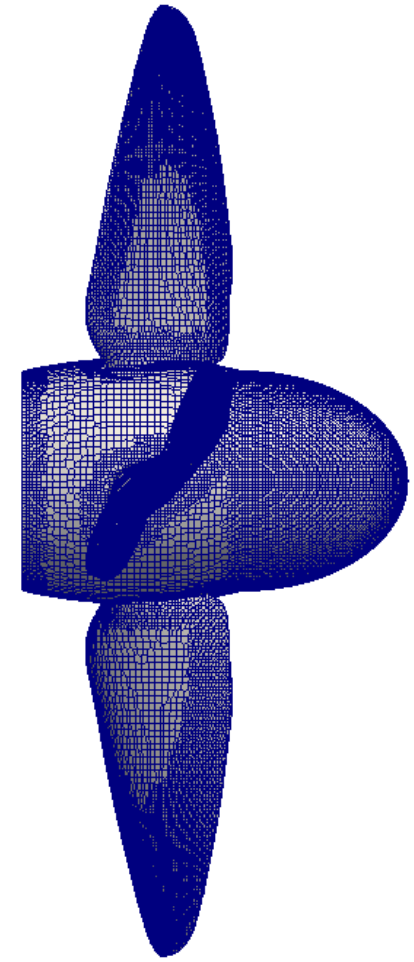

[c]

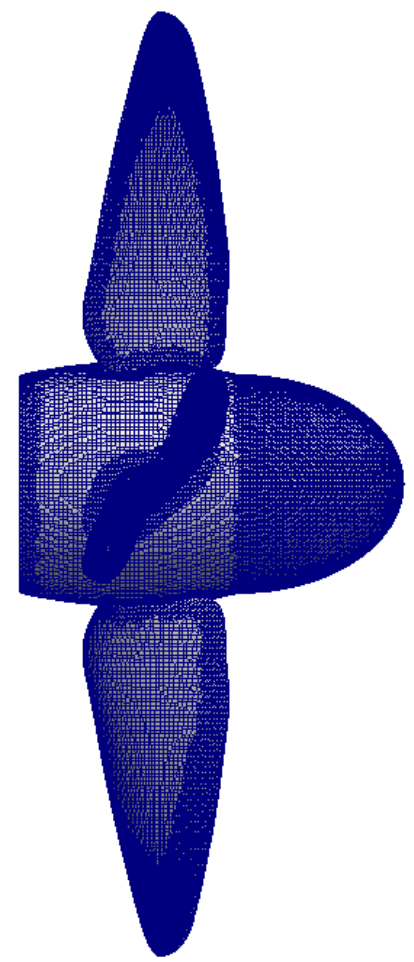

[d]

Fig. 5. Mesh cut showing (a) horizontal plane through hub centerline (medium grid) (b) propeller coarse grid 1.4M, cells (c) medium grid 3.3M, cells and (d) fine grid 8.8M cells. 

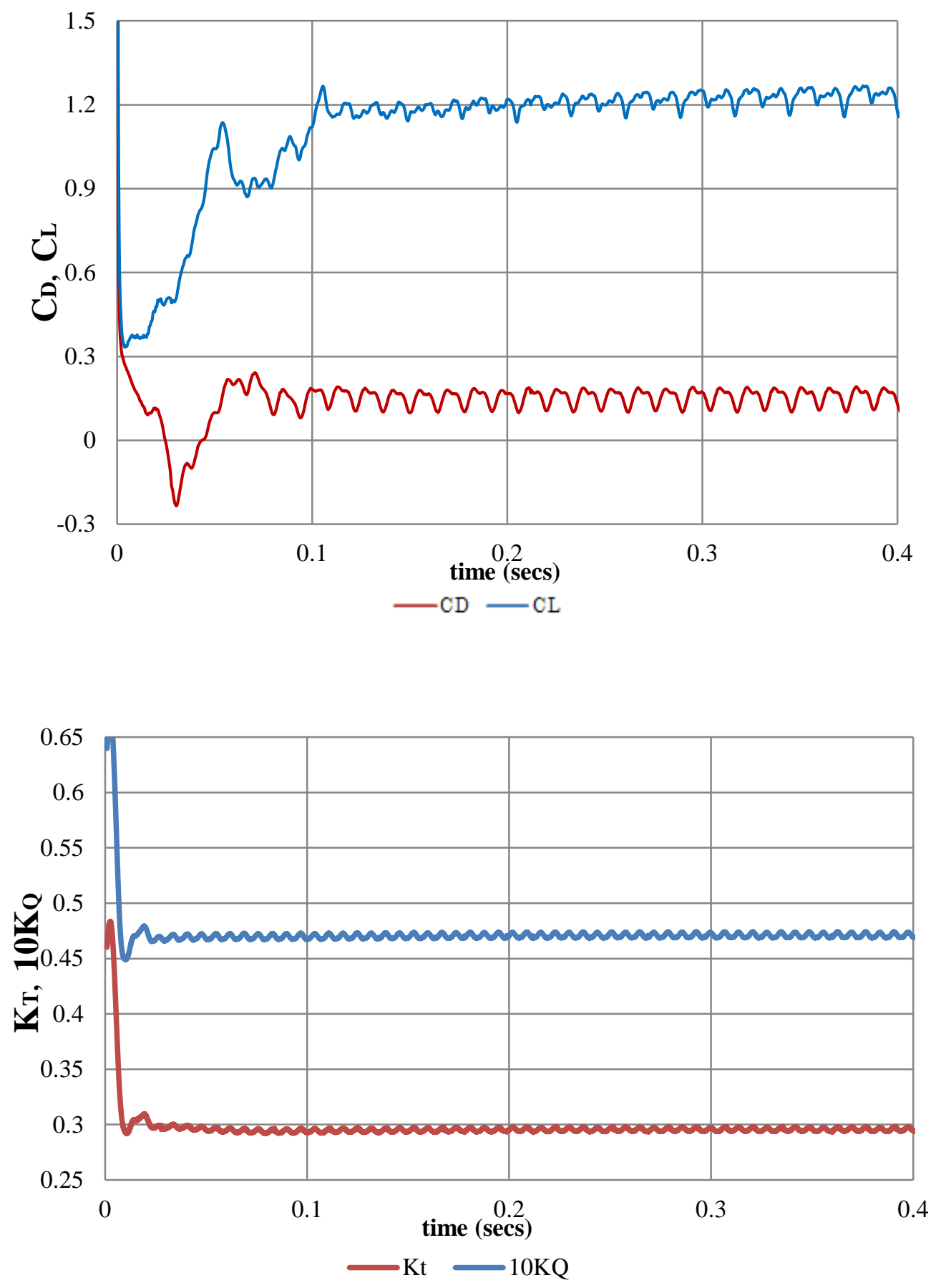

Fig. 6: Time history of propeller and rudder forces with medium grid, $\alpha=10^{\circ}, \beta_{R}=0^{\circ}, \mathrm{J}=$ 0.36 . 


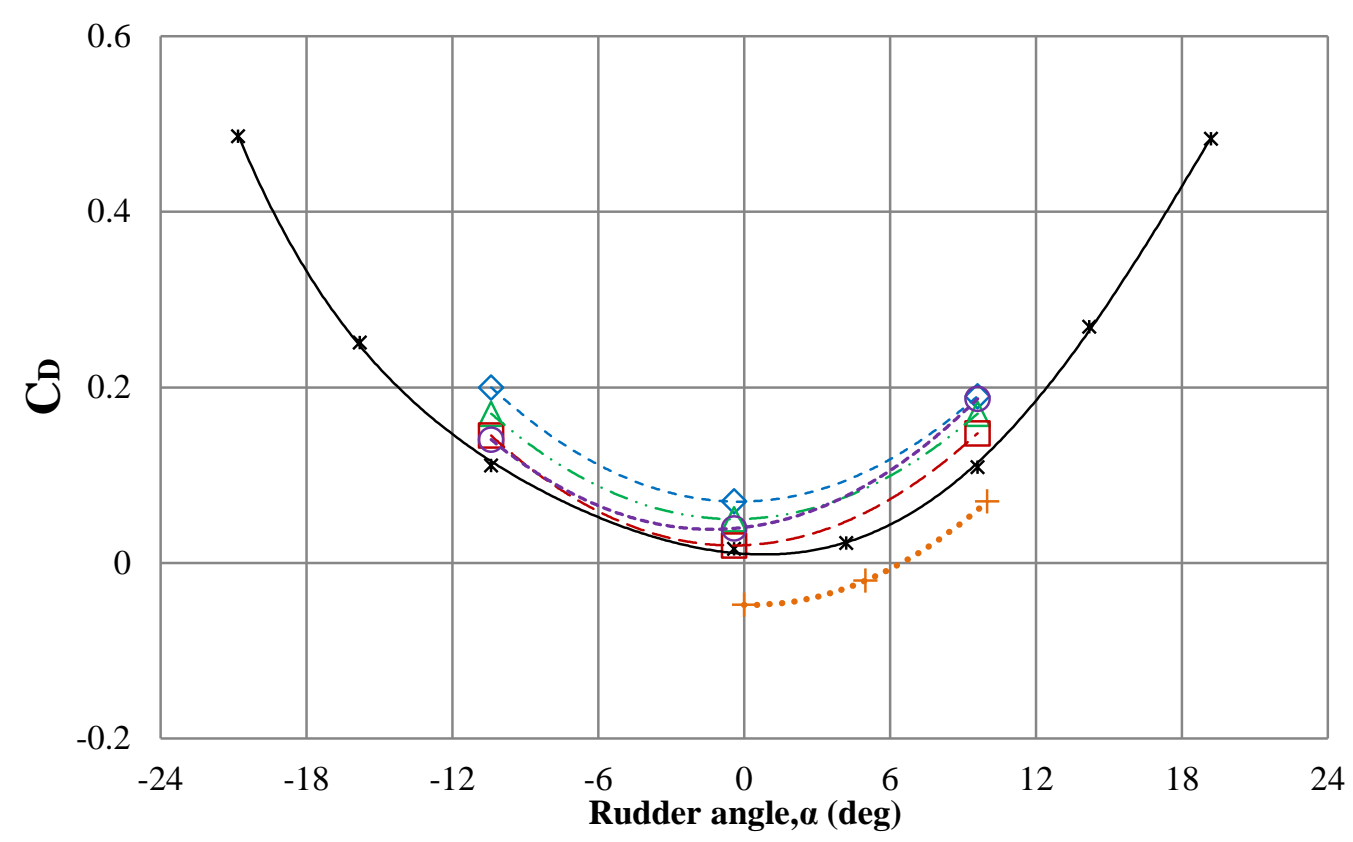

* Molland\&Turnock(1991) $\quad \diamond$ Coarse grid

$\triangle$ Medium grid

$\square$ Fine grid

OPhillips(2009)

+ Simonsen(2000)

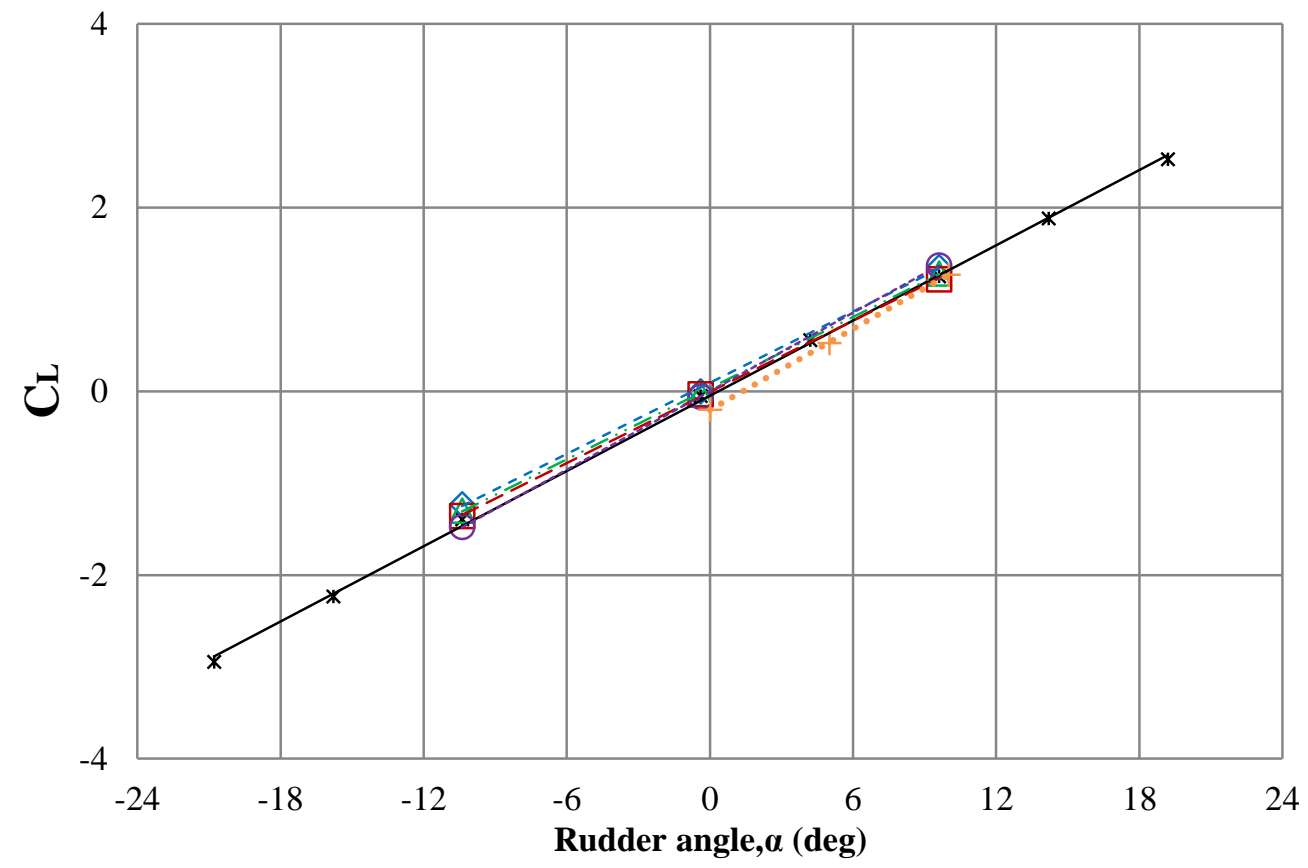

* Molland\&Turnock(1991) $\diamond$ Coarse grid

$\triangle$ Medium grid $\quad \square$ Fine grid

OPhillips(2009) + + Simonsen(2000)

Fig. 7. Rudder lift and drag coefficient for grid resolution study, $\beta_{R}=0^{\circ}, \mathrm{J}=0.36$. 

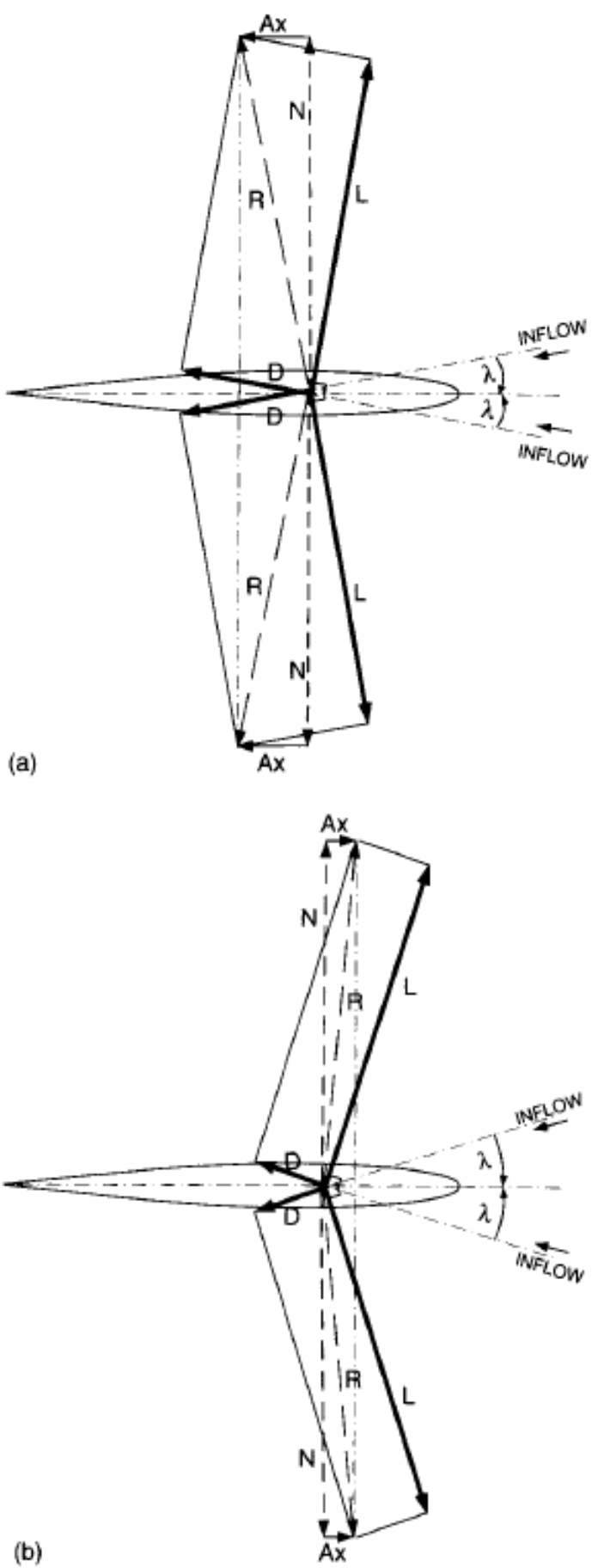

Fig. 8. (a) Rudder angle zero degrees: forces due to propeller-induced incidence; (b) Rudder angle zero: forces due to propeller-induced incidence - high thrust loading, source: Molland and Turnock, $(2007,2010)$. 


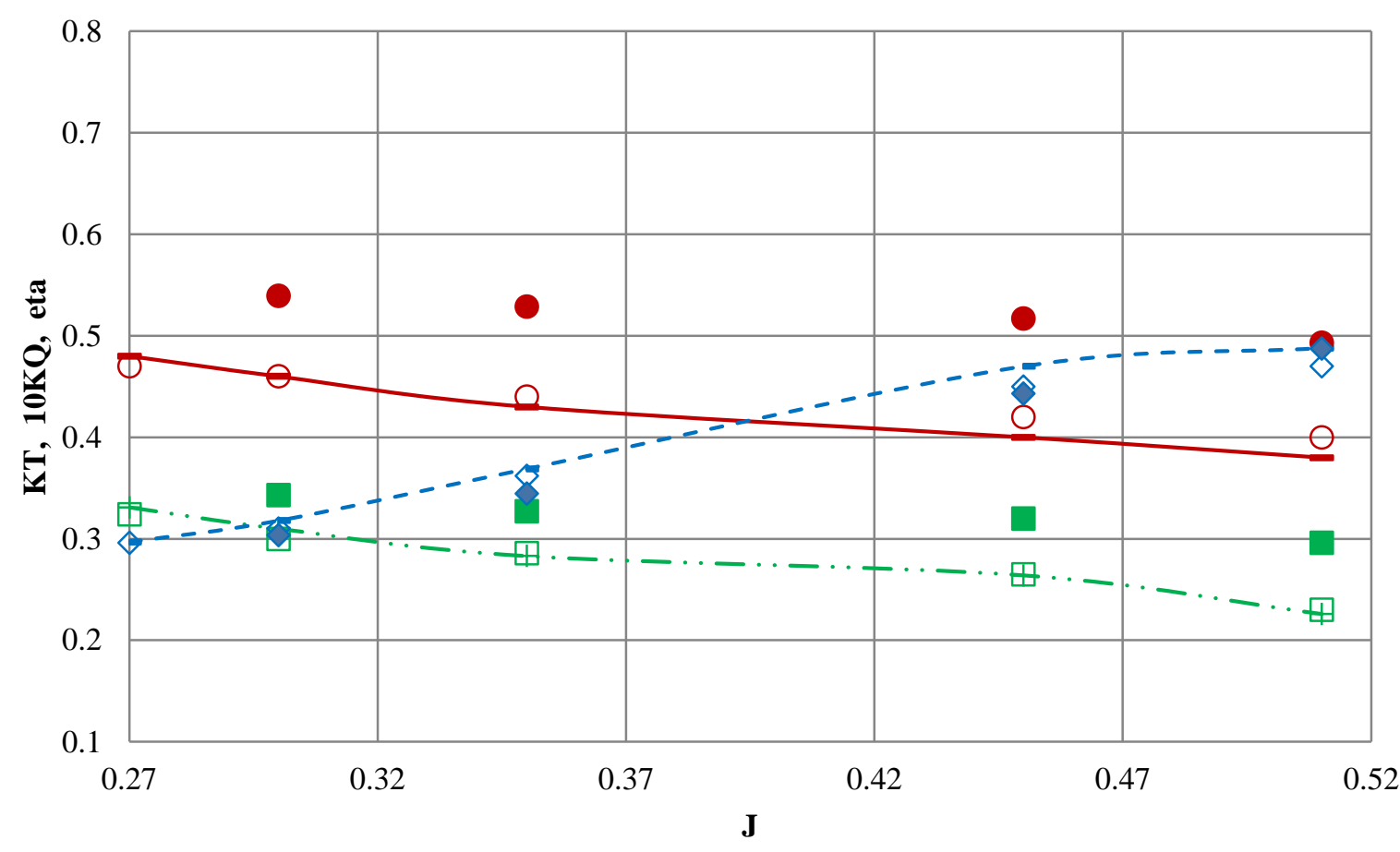

-+• - Odeg drift angle KT - Molland\&Turnock(1990)

—— 0 deg drift angle 10KQ - Molland\&Turnock(1990)

- - Odeg drift angle eta - Molland\&Turnock(1990)

$\square \quad$ Odeg drift angle KT - AMI

Odeg drift angle 10KQ - AMI

$\diamond \quad$ Odeg drift angle eta - AMI

-7.5deg drift angle KT - AMI

-7.5deg drift angle 10KQ - AMI

$-7.5 \mathrm{deg}$ drift angle eta - AMI

Fig. 9. Comparison of measured and computed propeller open-water characteristics; $\beta_{R}$ $=-7.5^{\circ} \& 0^{\circ}$. 


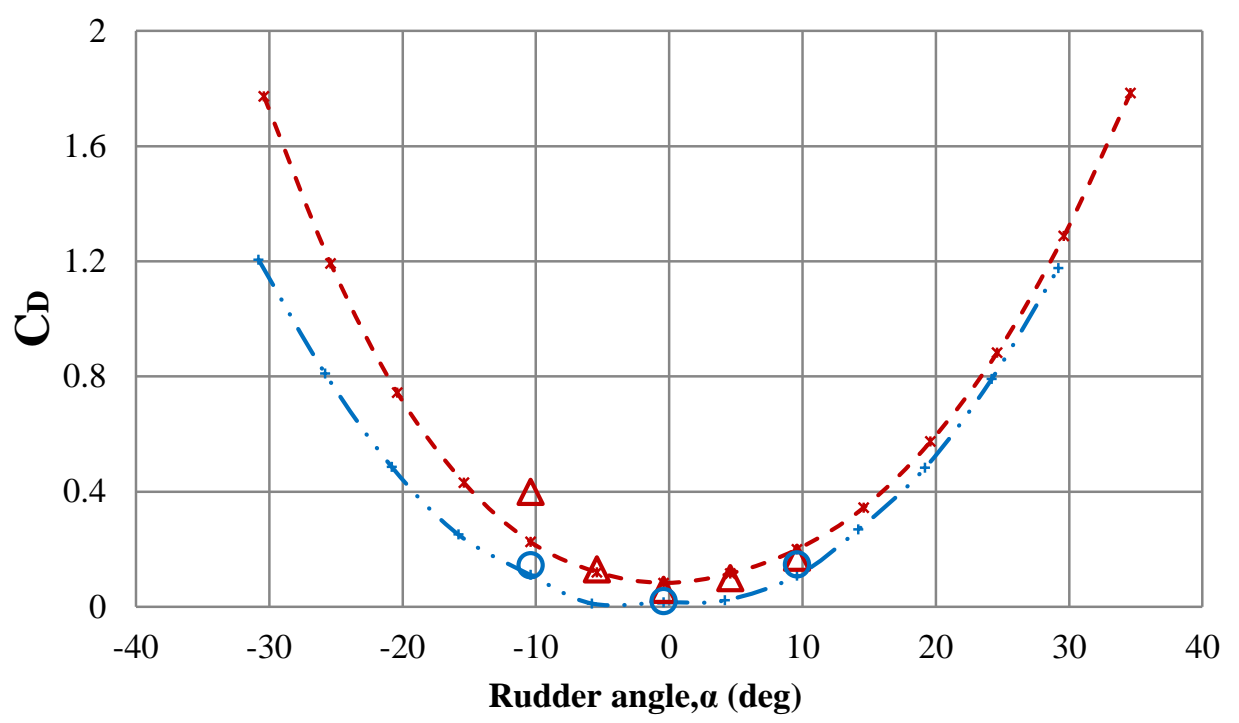

$-*-\quad-7.5$ deg drift angle Molland\&Turnock(1995)

$\Delta \quad-7.5 \mathrm{deg}$ drift angle AMI

- + - 0 deg drift angle Molland\&Turnock(1995)

O 0 deg drift angle AMI

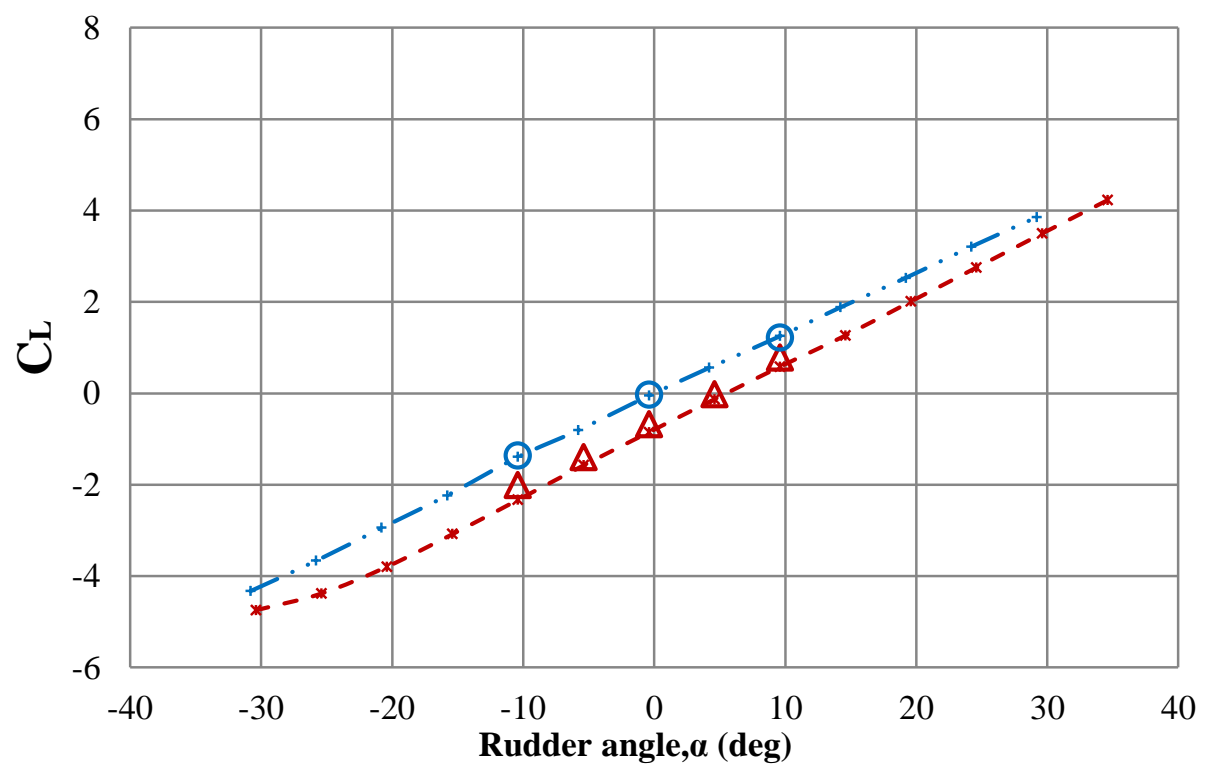

- * - -7.5deg drift angle Molland\&Turnock(1995)

$\Delta \quad-7.5 \mathrm{deg}$ drift angle AMI

- + - 0 deg drift angle Molland\&Turnock(1995)

O 0 deg drift angle AMI

Fig. 10. Effect of drift angle on the performance of a rudder and propeller combination in isolation at $\mathrm{J}=0.36, \beta_{R}=-7.5^{\circ}$ (medium grid results) and $\beta_{R}=0^{\circ}$ (fine grid results). 


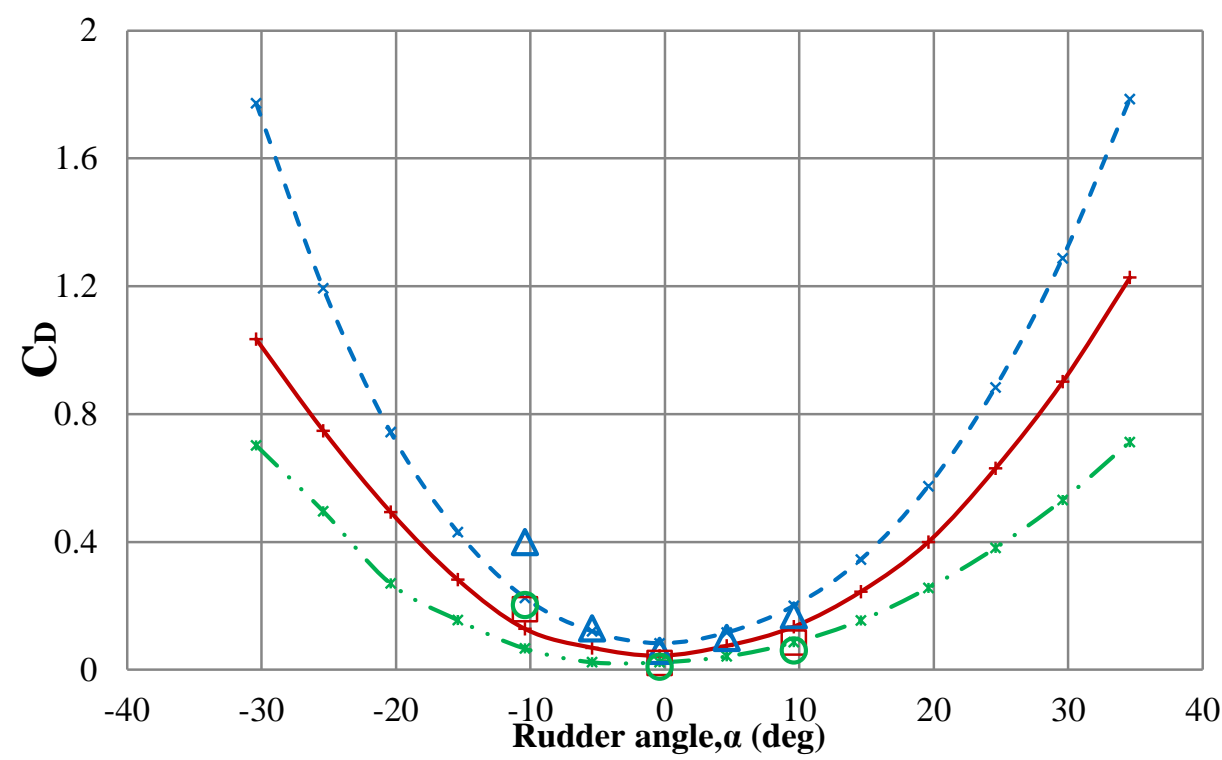

$-*-\cdot \mathrm{J}=0.36$ Molland\&Turnock(1995)

$\triangle \mathrm{J}=0.36$ AMI

\ $\mathrm{J}=0.51$ Molland\&Turnock(1995)

$\square \quad \mathrm{J}=0.51$ AMI

—* - J=0.94 Molland\&Turnock(1995)

○ J=0.94 AMI

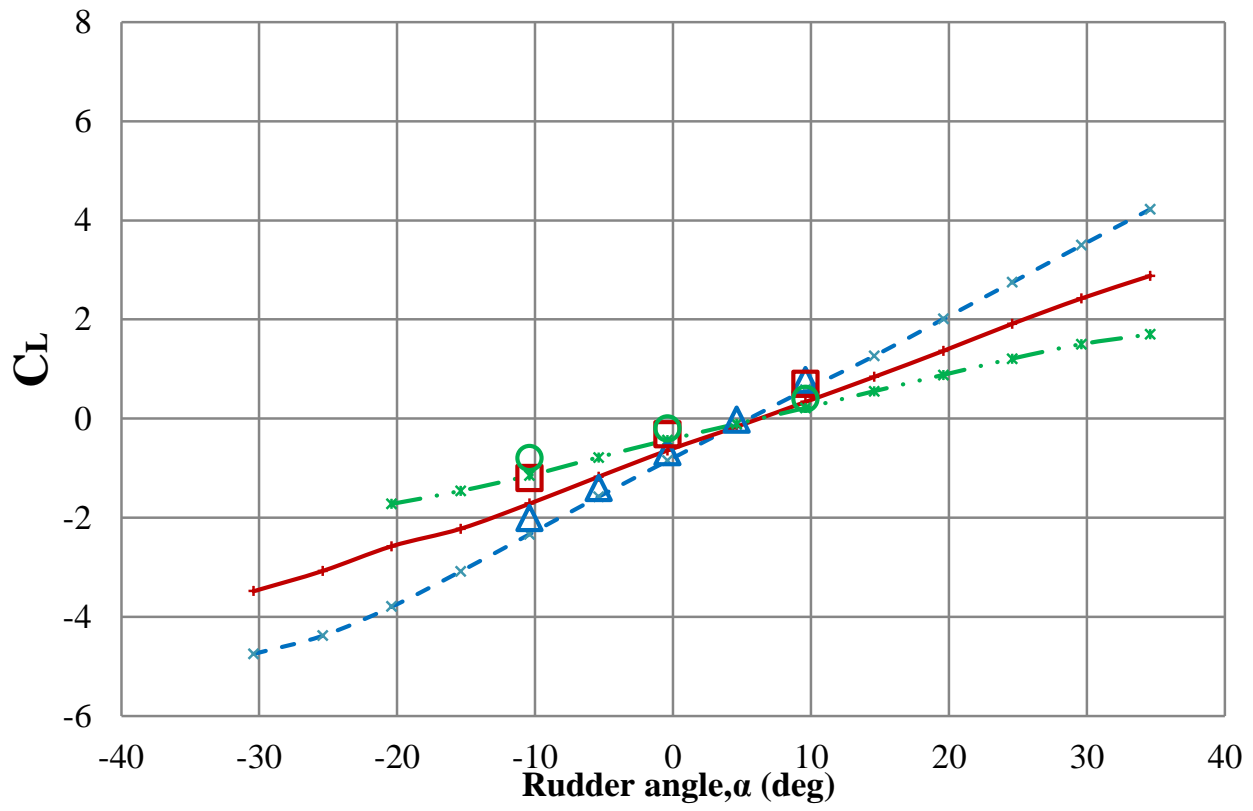

$-\rightarrow-\cdot J=0.36$ Molland\&Turnock(1995)

$\Delta \quad \mathrm{J}=0.36$ AMI

- J=0.51 Molland\&Turnock(1995)

$\square \quad \mathrm{J}=0.51$ AMI

- $\cdot-\mathrm{J}=0.94$ Molland\&Turnock(1995)

○ $\mathrm{J}=0.94$ AMI

Fig. 11. Effect of advance ratio on the performance of a rudder and propeller combination in isolation at drift angle, $\beta_{R}=-7.5^{0}$. 


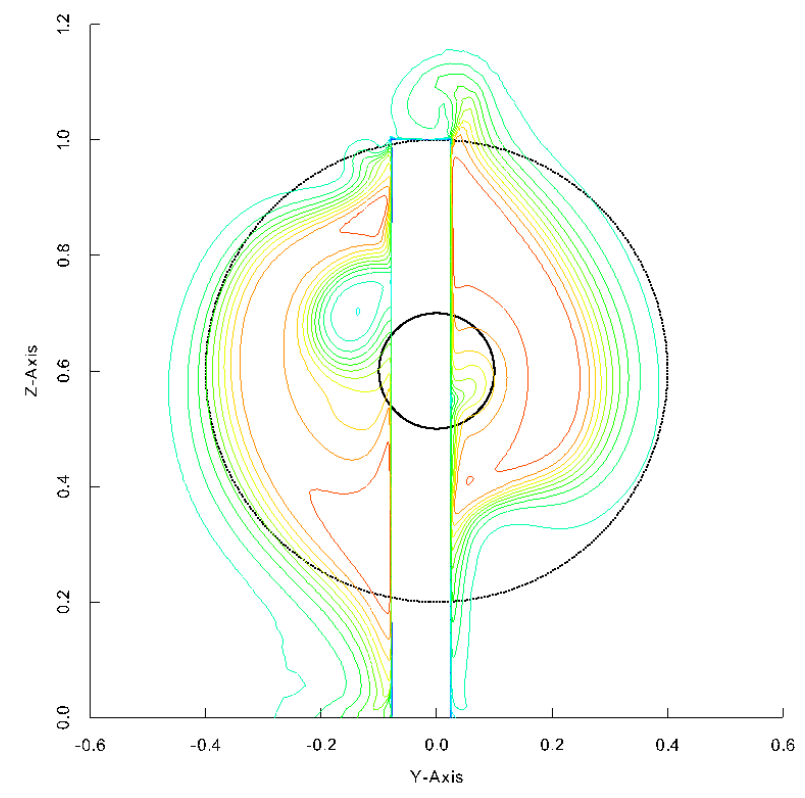

[a] $x=0.60$ chords (rudder mid chord)

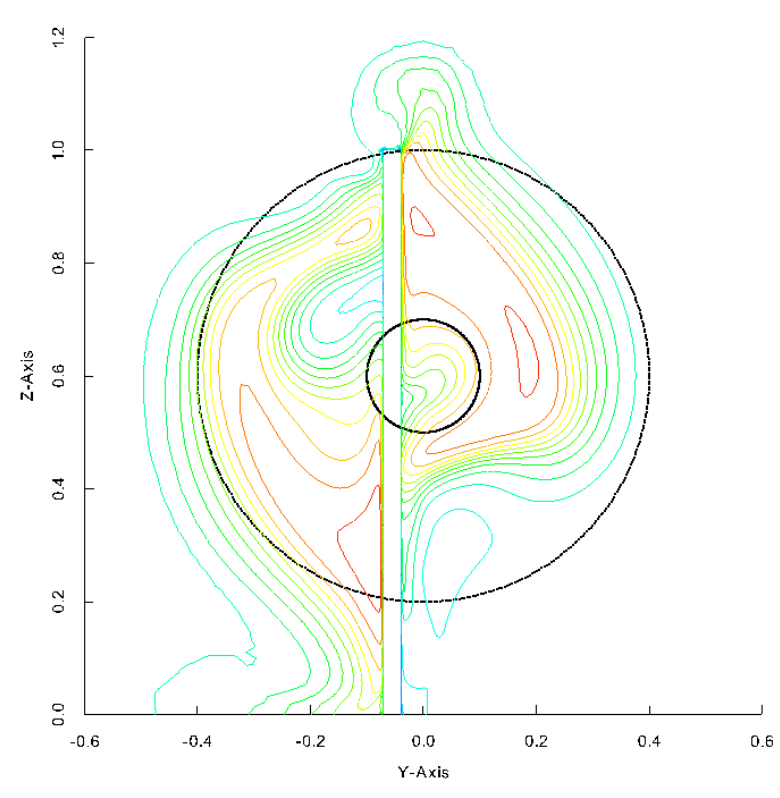

[b] $x=0.90$ chords (rudder trailing edge)

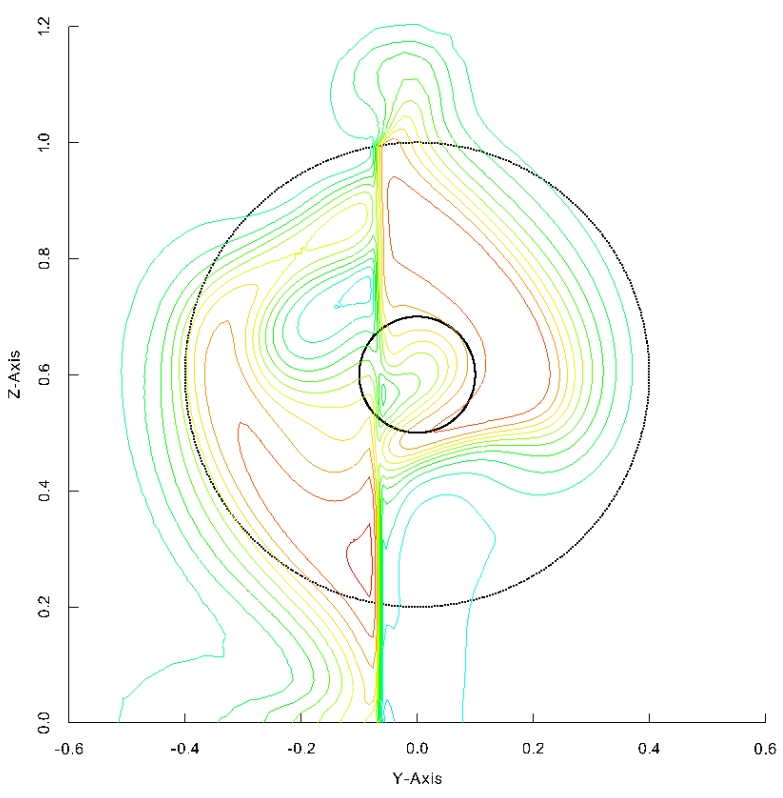

[c] $x=1.05$ chords (rudder wake)

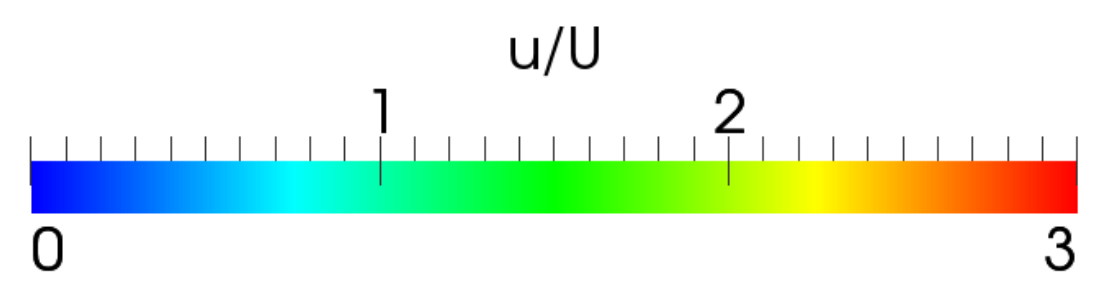

Fig. 12. Axial velocity contours at different rudder $x$-positions, $\mathrm{J}=0.36, \beta_{R}=-7.5^{\circ}$ at $\alpha=10^{\circ}$. 

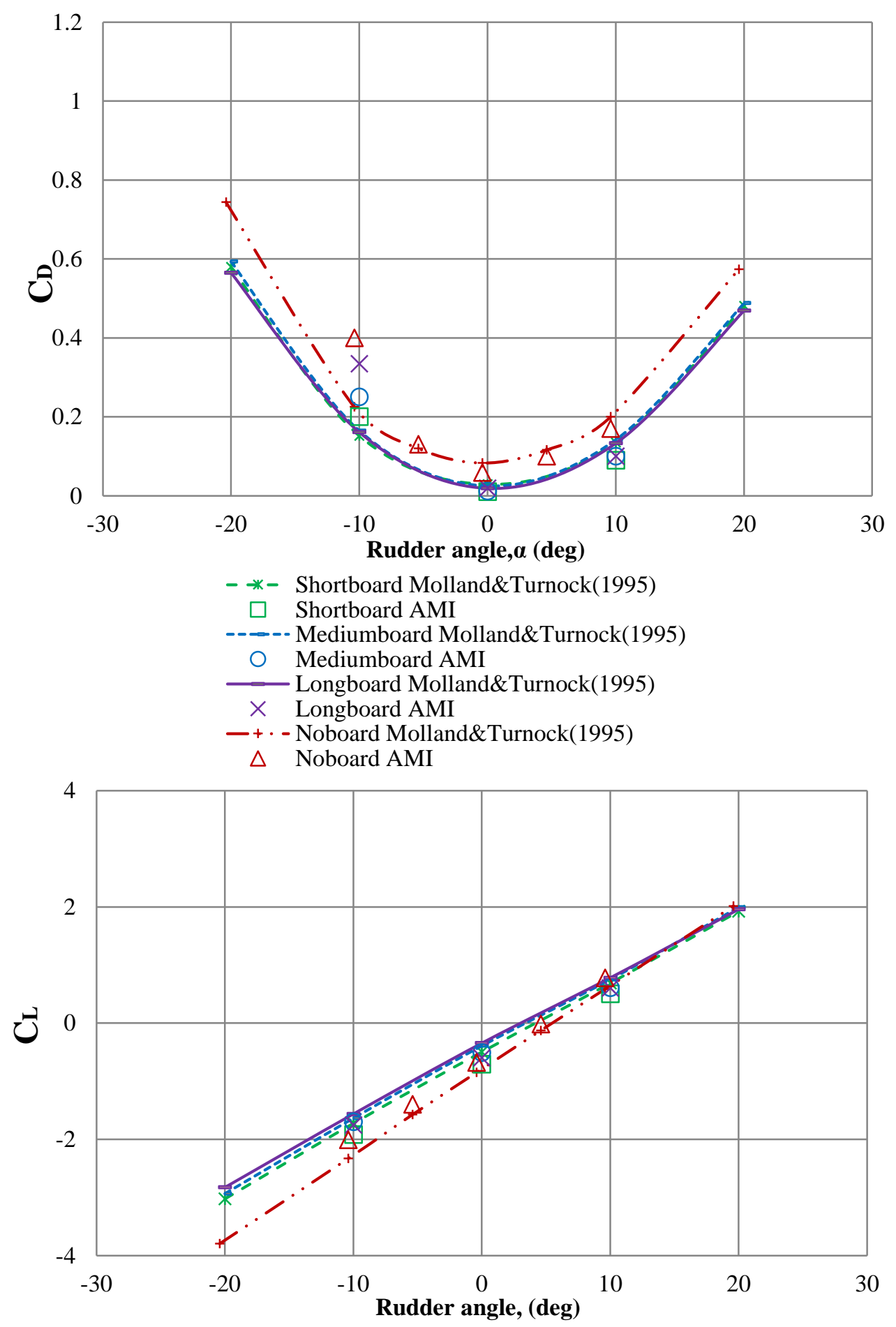

- *- Shortboard Molland\&Turnock(1995)

$\square \quad$ Shortboard AMI

----- Mediumboard Molland\&Turnock(1995)

O Mediumboard AMI

Longboard Molland\&Turnock(1995)

$\times \quad$ Longboard AMI

- + - - Noboard Molland\&Turnock(1995)

$\triangle$ Noboard AMI

Fig. 13. Effect of drift angle on the performance of a rudder downstream of three centreboard configurations at $\mathrm{J}=0.36, \beta_{R}=-7.5^{0}$. 


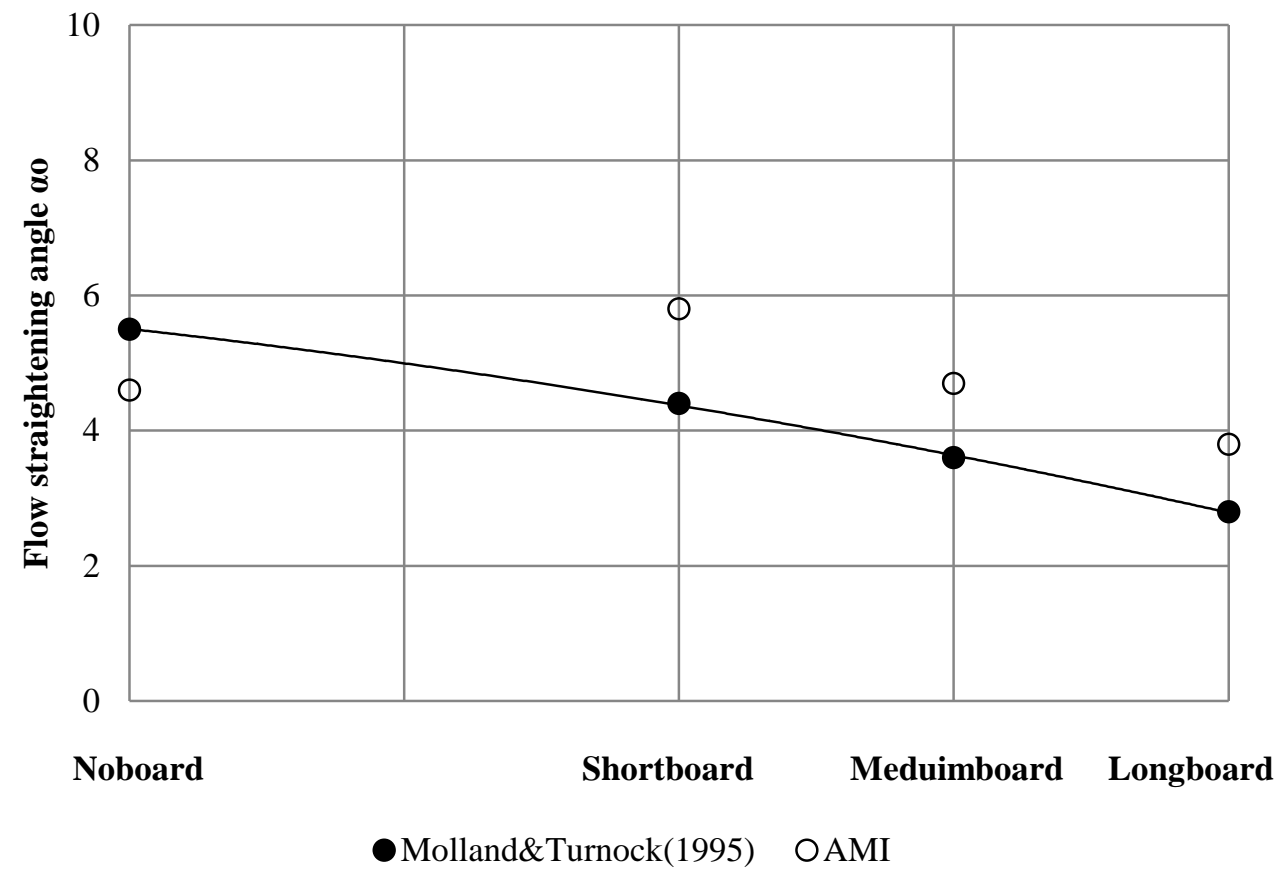

Fig. 14. Effect of propeller and centreline boards on flow straightening angle, $\alpha_{0}$.

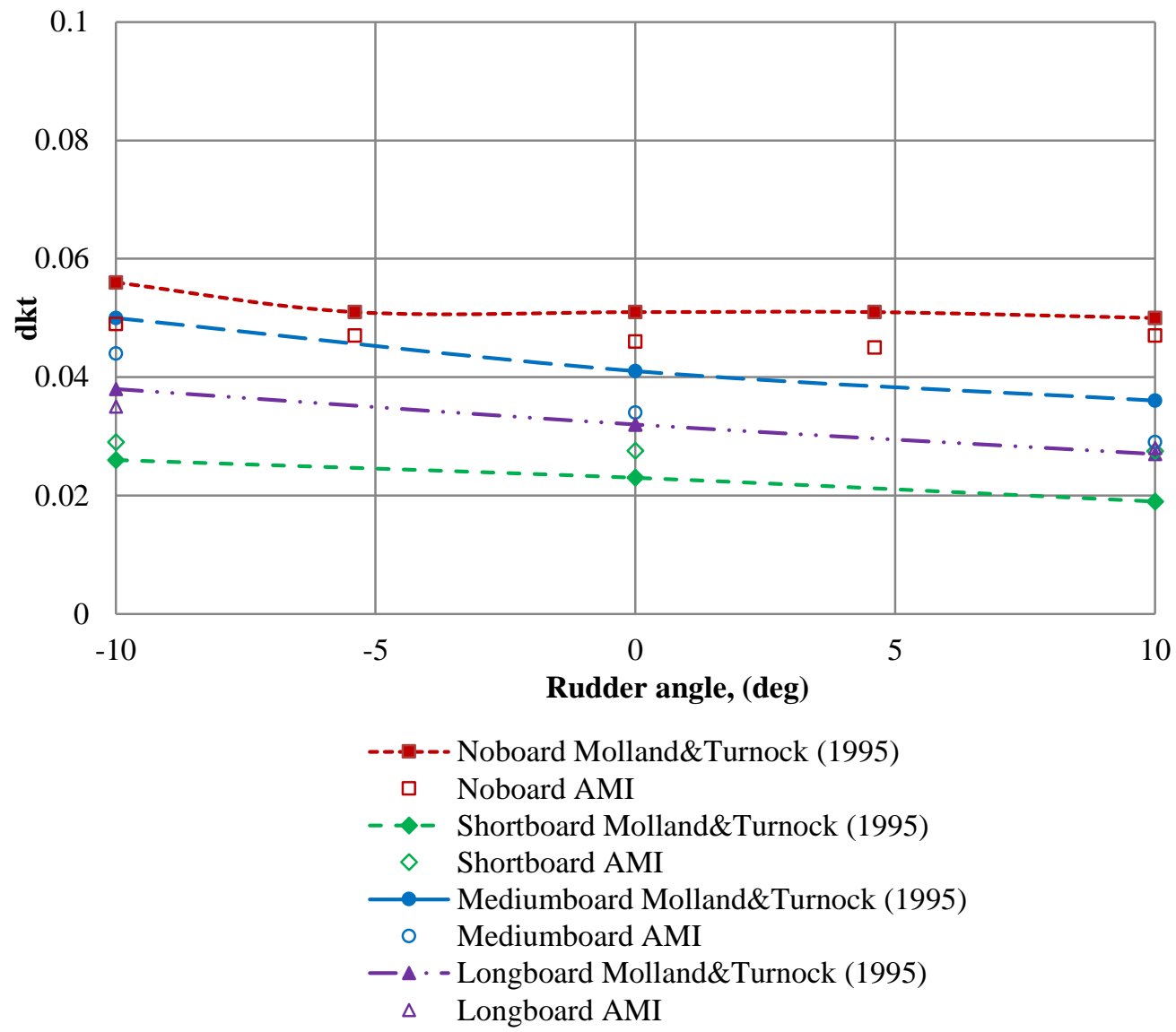

Fig. 15. Effect of drift angle on propeller thrust augments for rudder and propeller alone and different board lengths, $\mathrm{J}=0.36, \beta_{R}=-7.5^{\circ}$. 


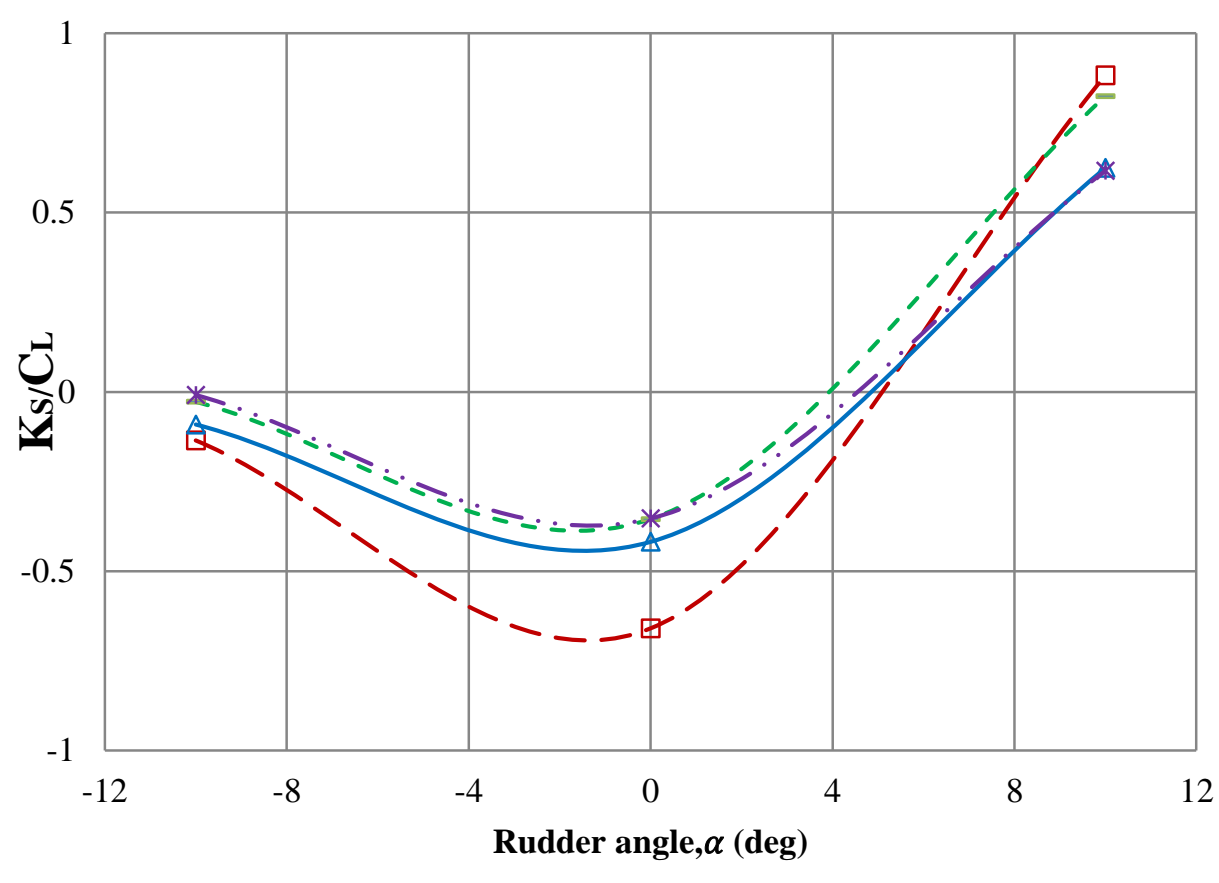

- - Noboard - - - Shortboard $\triangle$ Mediumboard —*.- Longboard

Fig. 16. Effect of board length on propeller side force, at $\mathrm{J}=0.36, \beta_{R}=-7.5^{\circ}$.

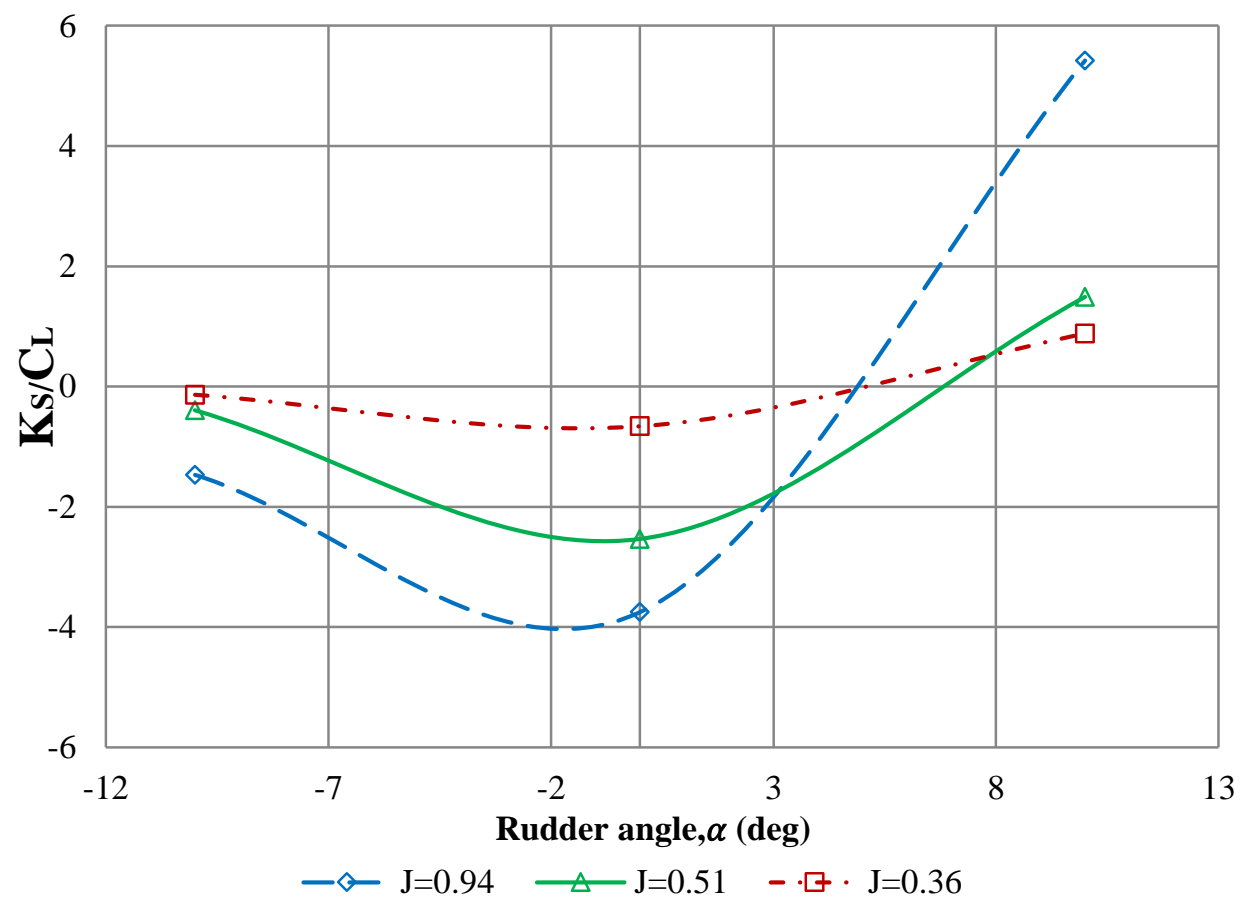

Fig. 17. Effect of advance ratio on propeller side force, rudder and propeller combination in isolation, $\beta_{R}=-7.5^{\circ}$. 


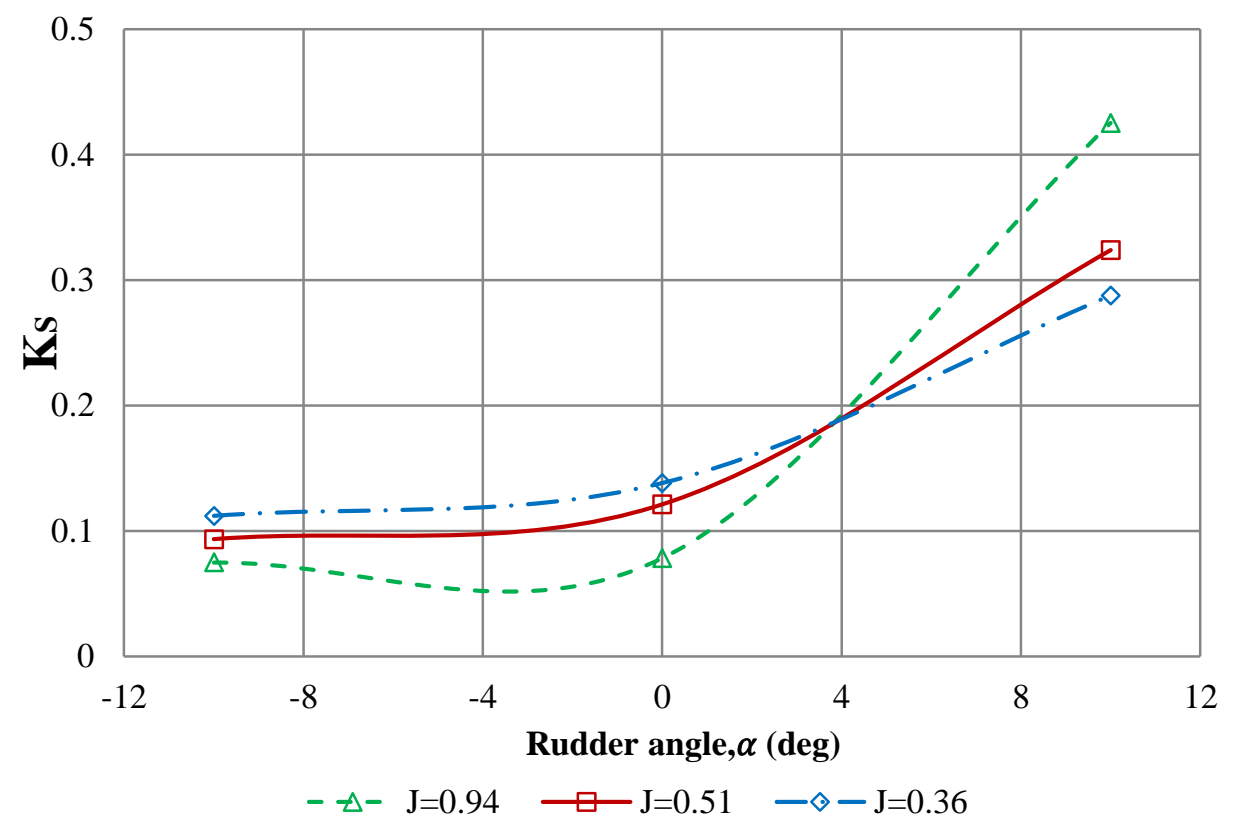

Fig. 18. Effect of advance ratio on propeller side force, rudder and propeller combination in isolation, $\beta_{R}=0^{\circ}$.

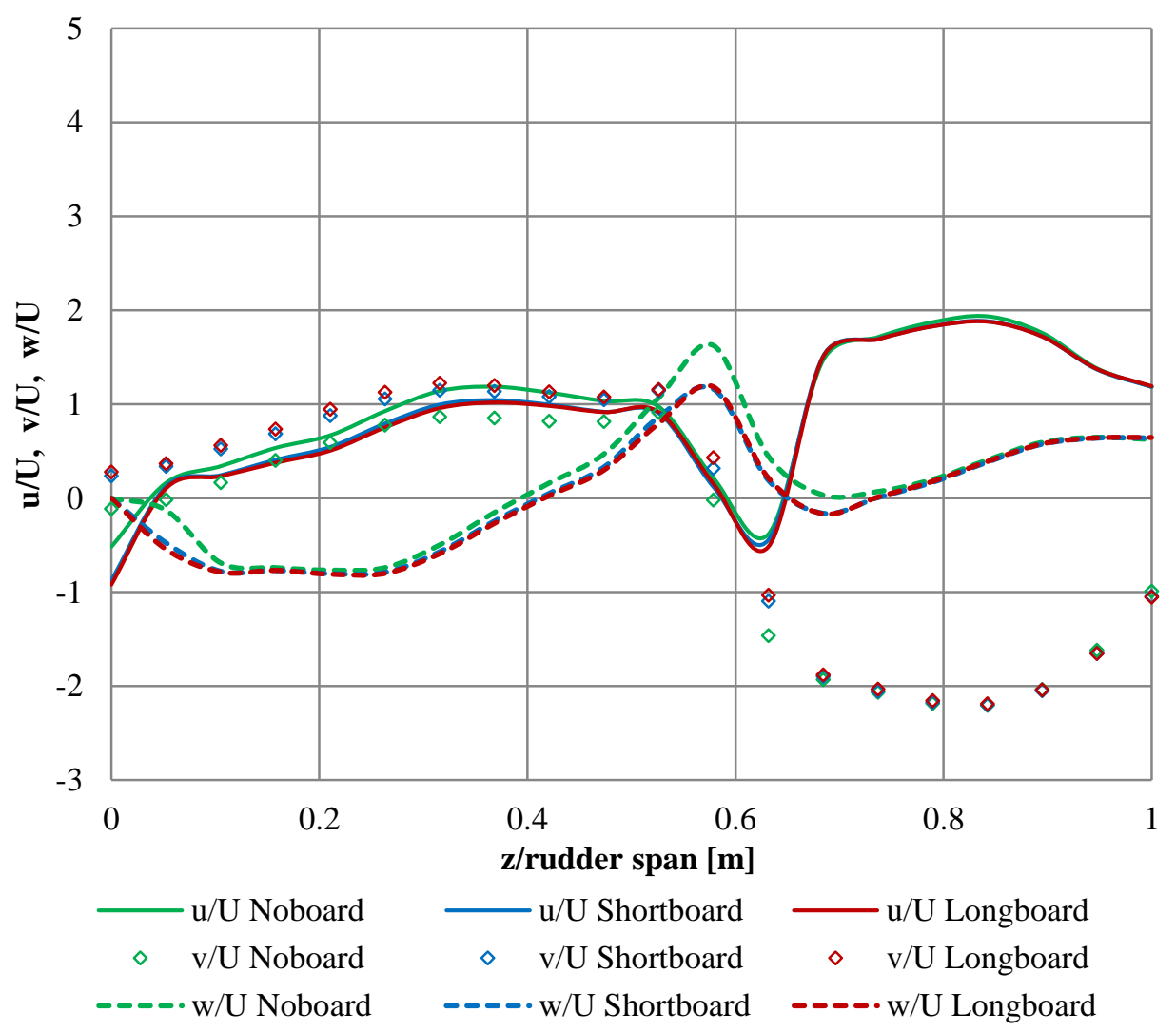

Fig. 19. Velocity downstream of the propeller plane $(X / D=0.374)$ at $y=0, J=0.36, \beta_{R}$ $=-7.5^{\circ}, \alpha=0^{\circ}$. 


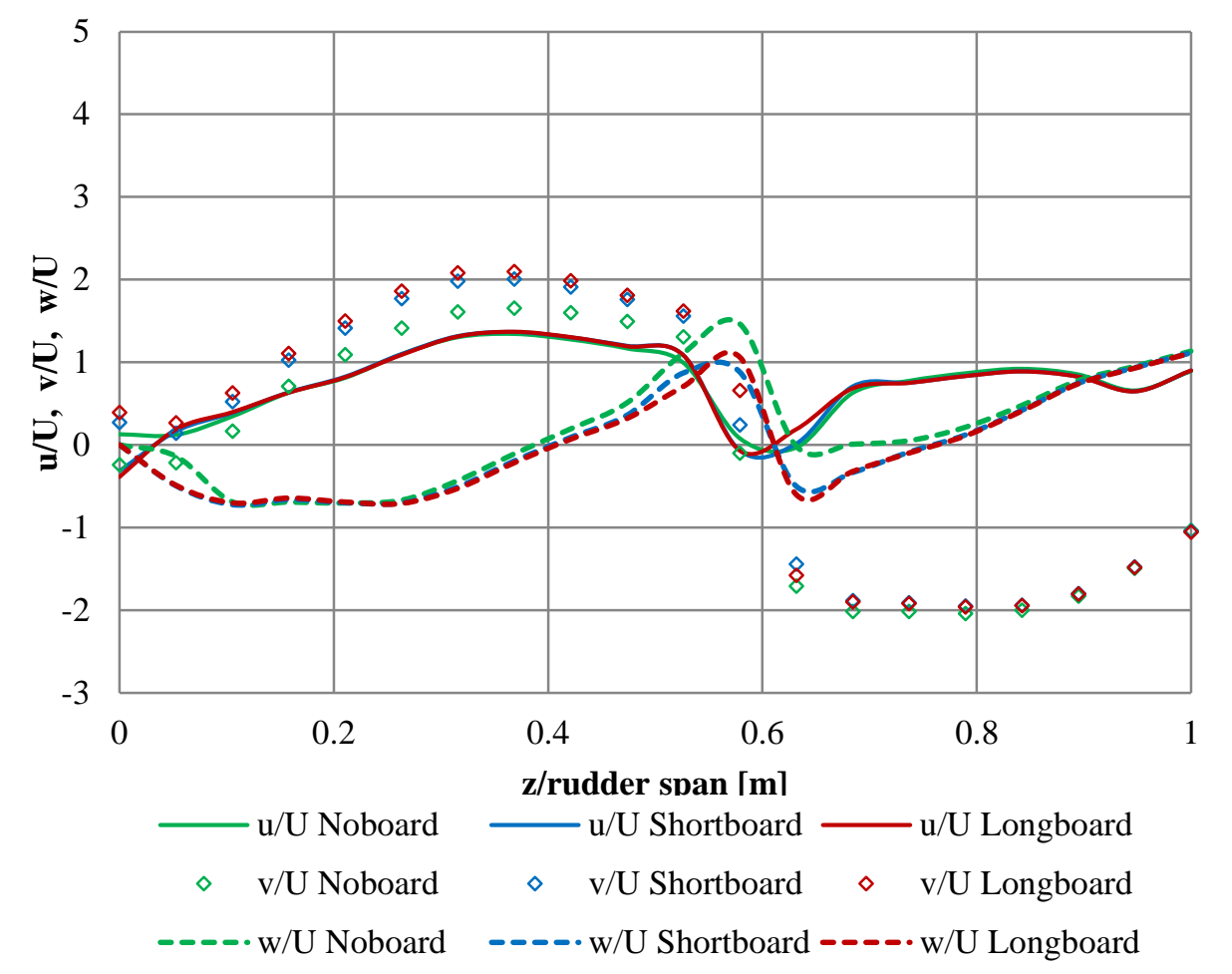

Fig. 20. Velocity downstream of the propeller plane $(X / D=0.374)$ at $y=0, J=0.36, \beta_{R}$ $=-7.5^{\circ}, \alpha=10^{\circ}$.
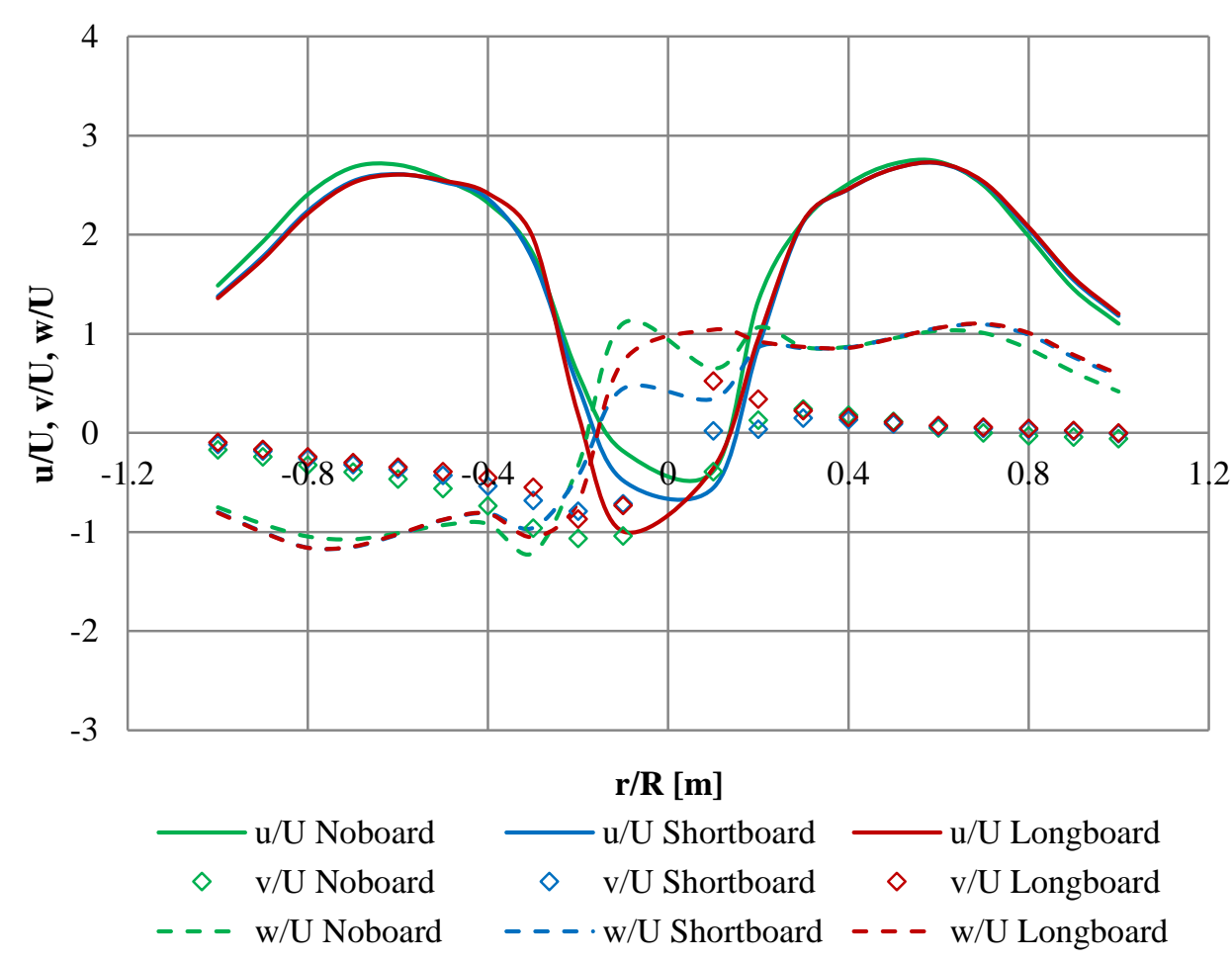

Fig. 21. Velocity downstream of the propeller plane $(X / D=0.374)$ at $z=0.6, J=0.36, \beta_{R}$

$$
=-7.5^{\circ}, \alpha=10^{\circ}
$$




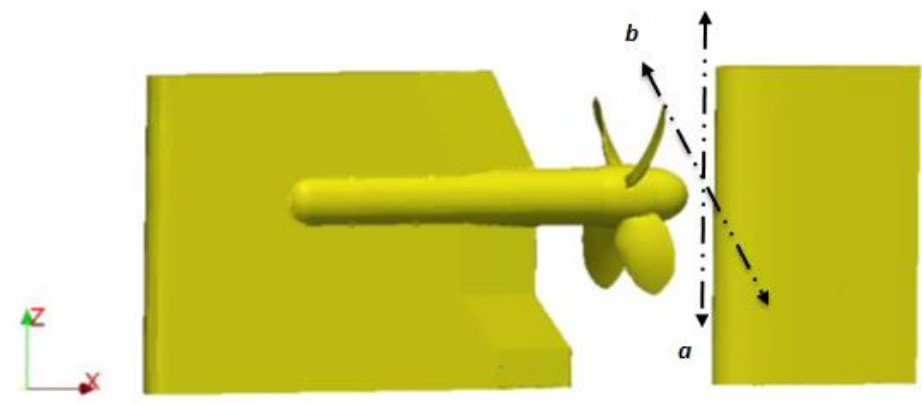

Fig. 22. Wake cut location for plots of velocity downstream of the propeller plane (a) at $\mathrm{y}=0$, (b) at $\mathrm{z}=0.6$ 


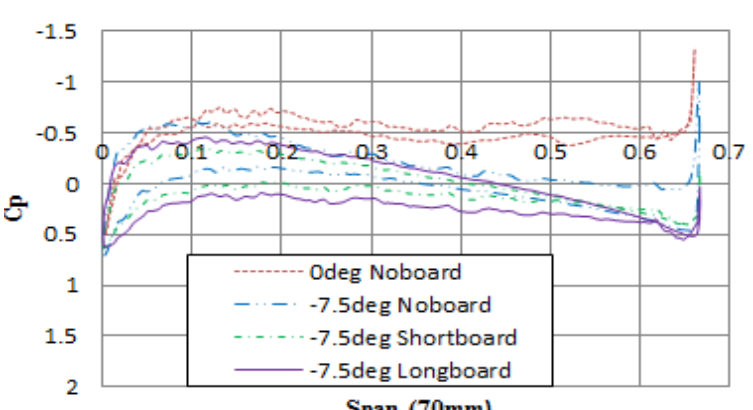

Span $(70 \mathrm{~mm})$

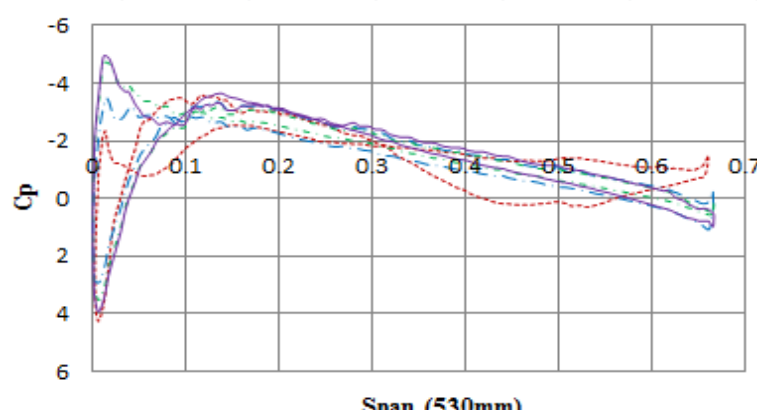

Span (530mm)

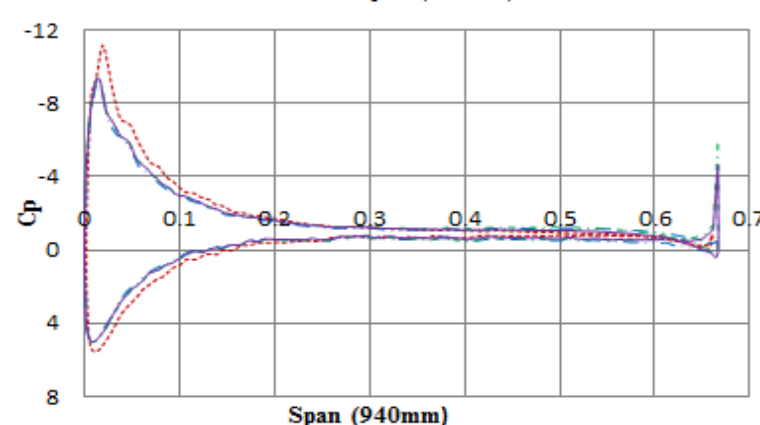

Span $(940 \mathrm{~mm})$

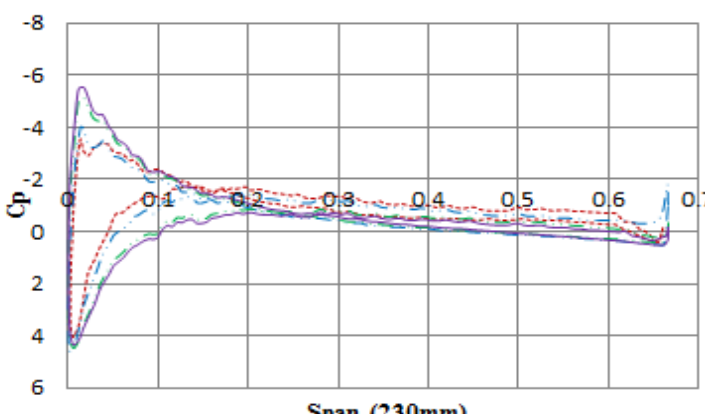

Span $(230 \mathrm{~mm})$

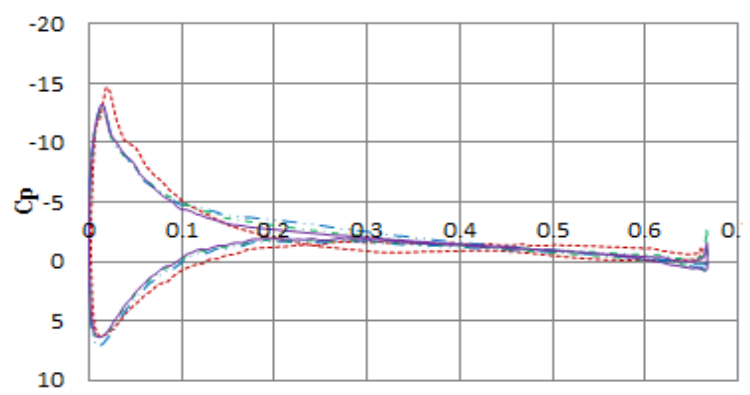

Span $(705 \mathrm{~mm})$

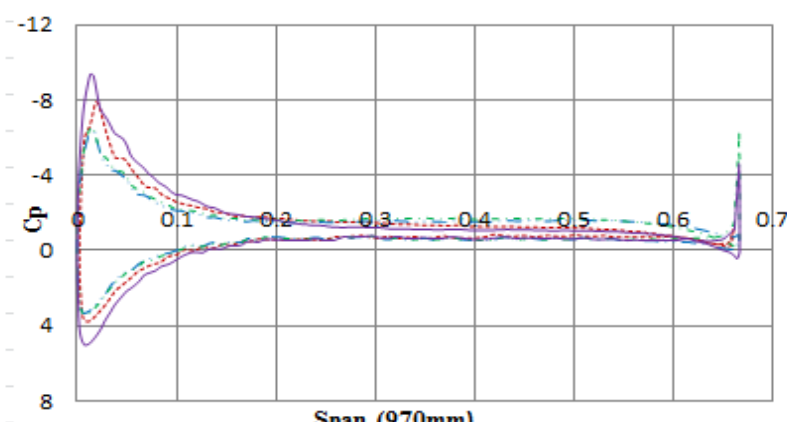

Span $(970 \mathrm{~mm})$

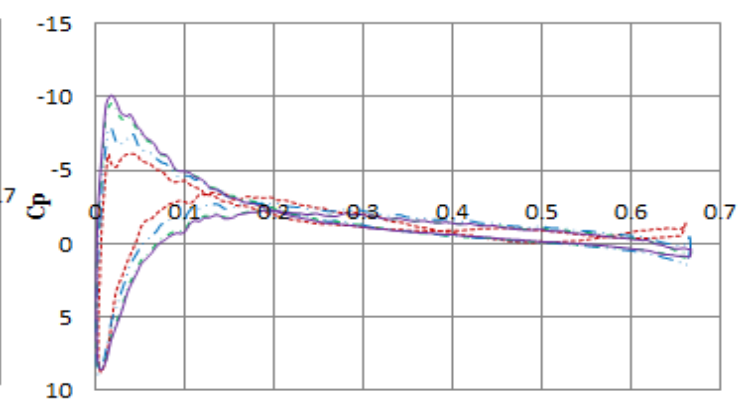

Span $(390 \mathrm{~mm})$

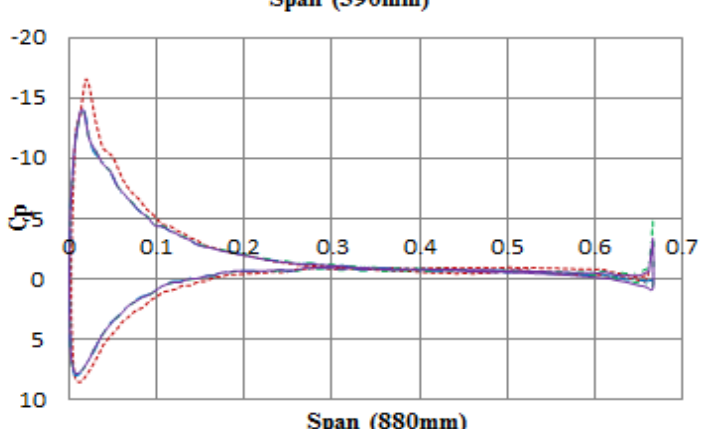

Span $(880 \mathrm{~mm})$

Fig. 23. Chordwise pressure distribution at various rudder spanwise positions, $\mathrm{J}=036, \beta_{R}=-7.5^{0} \& 0^{\circ}, \alpha=10^{\circ}$ 
Table 1: Geometric parameters of propeller and rudder.

\begin{tabular}{ll}
\hline & Settings \\
Parameter & $800 \mathrm{~mm}$ \\
Propeller diameter, $\mathrm{D}_{\mathrm{p}}$ & 4 \\
Number of blades, N & 0 to 3000 \\
Range of propeller revolutions r.p.m & 0.40 \\
Blade area ratio, BAR & $200 \mathrm{~mm}$ \\
Boss diameter (max), $\mathrm{D}_{\mathrm{h}}$ & 0.95 \\
P/D at 0.7R & $0.0 \mathrm{deg}$ \\
Rake & 0.050 \\
Propeller blade root thickness ratio & Wageningen B series \\
Propeller section shape & Wageningen B series with reduced skew \\
Propeller blade outline shape & $667 \mathrm{~mm}$ \\
Rudder chord & $1000 \mathrm{~mm}$ \\
Rudder span & NACA 0020 aerofoil section. \\
Rudder section shape & $30 \%$ of chord from leading edge \\
Rudder pivot point & 0.39 from propeller plane to rudder leading edge at $0^{\circ}$ \\
Rudder-Propeller separation, X/D & $1490 \mathrm{~mm}$ \\
Short centerboard length & $2090 \mathrm{~mm}$ \\
Medium centerboard length & $2690 \mathrm{~mm}$ \\
Long centerboard length &
\end{tabular}

Table 2: Simulation flow conditions.

\begin{tabular}{lllll}
\hline Test & $\begin{array}{l}\text { Free stream } \\
\text { velocity } \\
(\mathrm{m} / \mathrm{s})\end{array}$ & $\begin{array}{c}\text { Propeller } \\
\text { advance ratio, } J\end{array}$ & $\begin{array}{l}\text { Drift } \\
\text { angles } \\
\beta_{R}(\mathrm{deg})\end{array}$ & $\begin{array}{c}\text { Geometric rudder } \\
\text { angles } \\
\alpha(\mathrm{deg})\end{array}$ \\
\hline Rudder\&Prop alone & 10 & $0.36,0.51,0.94$ & 0 & $-10.4,-0.4,9.6$ \\
Rudder\&Prop alone & 10 & $0.36,0.51,0.94$ & -7.5 & $-10.4,-5.4,-0.4,4.6,9.6$ \\
Short centreboard & 10 & 0.36 & -7.5 & $-10.4,-0.4,9.6$ \\
Medium centerboard & 10 & 0.36 & -7.5 & $-10.4,-0.4,9.6$ \\
Long centreboard & 10 & 0.36 & -7.5 & $-10.4,-0.4,9.6$
\end{tabular}

NOTE: Rudder angles selected to exactly match the wind tunnel experiments.

Table 3: Computational parameters.

\begin{tabular}{ll}
\hline & Settings \\
\hline Parameter & Iridis 3 Linux Cluster \\
Mesh type & Unstructured hexahedral \\
Turbulence model & Shear Stress Transport, Menter, (1994) \\
Pressure-velocity coupling & PIMPLE \\
$y^{+}$average (rudder) & 30 \\
Grad (U) Scheme & Gauss linear \\
Div (U) & Gauss linear upwind \\
Convergence criteria & RMS residual $<10^{-8}$ \\
Run type & Parallel $(12$ partitions run on 6x Dual core nodes $)$ \\
\hline
\end{tabular}


Table 4: Grid system used for sensitivity analysis

\begin{tabular}{llll}
\hline Parameter & Coarse grid & Medium grid & Fine grid \\
\hline BlockMesh refinement & $80 \times 18 \times 36$ & $113 \times 24 \times 51$ & $160 \times 36 \times 72$ \\
Cells in rotating region & $150 \mathrm{~K}$ & $300 \mathrm{~K}$ & $770 \mathrm{~K}$ \\
Cells in stationary region & $1.2 \mathrm{M}$ & $2.9 \mathrm{M}$ & $8.0 \mathrm{M}$ \\
Total no of cells (approx.) & $1.4 \mathrm{M}$ & $3.3 \mathrm{M}$ & $8.8 \mathrm{M}$ \\
Computational expense & $20-22 \mathrm{hrs}$ & $60-65 \mathrm{hrs}$ & $170-180 \mathrm{hrs}$ \\
\hline
\end{tabular}

NB: Computational expenses are based on parallel run of 12 partitions run on 6 core nodes for approximately 20 propeller revolutions. All times are in wall clock hours

Table 5: Grid sensitivity study for propeller and rudder forces, $\alpha=10^{\circ}, \beta_{R}=0^{\circ}, \mathrm{J}=0.36$.

\begin{tabular}{|c|c|c|c|c|c|c|}
\hline Grid & Coarse grid & Medium grid & Fine grid & $\begin{array}{l}\text { Simonsen } \\
(2000)\end{array}$ & $\begin{array}{l}\text { Phillips et al. } \\
(2010)\end{array}$ & Data \\
\hline $\begin{array}{l}\mathrm{K}_{\mathrm{T}} \\
\varepsilon\end{array}$ & $\begin{array}{c}0.305 \\
+7.77 \%\end{array}$ & $\begin{array}{c}0.294 \\
+3.89 \%\end{array}$ & $\begin{array}{l}0.286 \\
+1.06 \%\end{array}$ & - & - & 0.283 \\
\hline $\begin{array}{l}\mathrm{K}_{\mathrm{Q}} \\
\varepsilon\end{array}$ & $\begin{array}{c}0.051 \\
+18.60 \%\end{array}$ & $\begin{array}{l}0.047 \\
+9.30 \%\end{array}$ & $\begin{array}{l}0.044 \\
+2.32 \%\end{array}$ & - & - & 0.043 \\
\hline $\begin{array}{l}\mathrm{C}_{\mathrm{L}} \\
\varepsilon\end{array}$ & $\begin{array}{l}1.35 \\
+7.96 \%\end{array}$ & $\begin{array}{l}1.28 \\
+2.36 \%\end{array}$ & $\begin{array}{l}1.22 \\
-2.44 \%\end{array}$ & $\begin{array}{r}1.27 \\
+1.56\end{array}$ & $\begin{array}{c}1.36 \\
+8.76\end{array}$ & 1.2505 \\
\hline $\begin{array}{l}\mathrm{C}_{\mathrm{D}} \text { total } \\
\varepsilon\end{array}$ & $\begin{array}{c}0.19 \\
+74.3 \%\end{array}$ & $\begin{array}{l}0.17 \\
+55.96 \%\end{array}$ & $\begin{array}{l}0.148 \\
+35.78 \%\end{array}$ & $\begin{array}{l}0.07 \\
-93.58\end{array}$ & $\begin{array}{c}0.187 \\
+71.56\end{array}$ & 0.109 \\
\hline$C_{D}$ viscous & 0.075 & 0.072 & 0.069 & - & - & - \\
\hline$C_{D}$ pressure & 0.115 & 0.098 & 0.079 & - & - & - \\
\hline
\end{tabular}

Table 6: Uncertainty analysis-propeller and rudder forces at $\alpha=10^{\circ}, \beta_{R}=0^{\circ}, \mathrm{J}=0.36$.

\begin{tabular}{cccccc}
\hline Study & $\boldsymbol{R}_{\boldsymbol{G}}$ & $\boldsymbol{P}_{\boldsymbol{G}}$ & $\boldsymbol{C}_{\boldsymbol{G}}$ & $\boldsymbol{U}_{\boldsymbol{G}}$ & $\boldsymbol{S}_{\boldsymbol{C}}$ \\
\hline $\boldsymbol{K}_{\boldsymbol{T}}$ & 0.72 & 0.92 & 0.38 & $7.1 \%$ & 0.283 \\
$\boldsymbol{K}_{\boldsymbol{Q}}$ & 0.75 & 0.83 & 0.33 & $20.9 \%$ & 0.043 \\
$\boldsymbol{C}_{\boldsymbol{L}}$ & 0.86 & 0.44 & 0.16 & $29.0 \%$ & 1.251 \\
\hline
\end{tabular}


Table 7: Comparison of average propeller thrust and torque coefficients at drift, $\beta_{R}=-7.5^{0}$.

\begin{tabular}{|c|c|c|c|c|}
\hline & \multicolumn{2}{|c|}{$\mathrm{K}_{\mathrm{T}}$ (average) } & \multicolumn{2}{|c|}{$\mathrm{K}_{\mathrm{Q}}$ (average) } \\
\hline & Molland\&Turnock & AMI & Molland\&Turnock & AMI \\
\hline Rudder\&Prop alone & 0.336 & 0.333 & 0.046 & 0.054 \\
\hline Short board & 0.306 & 0.314 & 0.051 & 0.051 \\
\hline Medium board & 0.325 & 0.322 & 0.051 & 0.051 \\
\hline Long board & 0.315 & 0.317 & 0.051 & 0.051 \\
\hline
\end{tabular}

Table 8: Rudder lift curve slope, $\partial C_{L} / \partial \alpha$ and corresponding drag at zero incidence, $C_{D_{0} \text {. }}$

\begin{tabular}{lcccc}
\hline & $C_{D_{0}}$ & & \multicolumn{2}{c}{$\partial C_{L} / \partial \alpha$} \\
& Molland\&Turnock & Calculations & Molland\&Turnock & Calculations \\
\hline Zero drift angle & 0.016 & 0.02 & 0.132 & 0.129 \\
Rudder \& propeller alone & 0.083 & 0.06 & 0.146 & 0.144 \\
Short board & 0.029 & 0.01 & 0.121 & 0.119 \\
Medium board & 0.025 & 0.012 & 0.119 & 0.115 \\
Long board & 0.0169 & 0.019 & 0.125 & 0.126 \\
\hline
\end{tabular}




\begin{tabular}{|c|c|c|c|c|c|c|c|c|c|c|c|c|c|c|}
\hline $\begin{array}{l}\text { Rudder } \\
\text { angle, } \alpha(\operatorname{deg})\end{array}$ & $\begin{array}{c}\beta \mathbf{r} \\
(\mathrm{deg})\end{array}$ & $\mathbf{K}_{\mathbf{T}}$ & $\mathbf{K}_{\mathbf{Q}}$ & $\mathbf{K}_{\mathbf{S}}$ & $\eta$ & $\mathbf{t}$ & wt & DKt & $\partial K q$ & $\mathbf{C}_{\mathrm{L}}$ & $\mathbf{C}_{\mathbf{D}}$ & \multicolumn{2}{|c|}{$\begin{array}{c}\text { Board drag } \\
{[\mathrm{N}]}\end{array}$} & $\begin{array}{c}\text { Board lift } \\
{[\mathrm{N}]}\end{array}$ \\
\hline \multicolumn{15}{|c|}{ Rudder\&Propeller alone, $\mathrm{J}=\mathbf{0 . 3 6}$} \\
\hline-10 & 0 & 0.397 & 0.054 & $1.12 \mathrm{E}-3$ & 0.480 & & & 0.111 & 0.01 & -1.360 & 0.145 & & & \\
\hline 0 & 0 & 0.390 & 0.053 & $1.38 \mathrm{E}-3$ & 0.486 & & & 0.104 & $0.90 \mathrm{E}-2$ & -0.034 & 0.020 & & & \\
\hline 10 & 0 & 0.334 & 0.053 & $2.88 \mathrm{E}-3$ & 0.476 & & & 0.048 & $0.90 \mathrm{E}-2$ & 1.220 & 0.148 & & & \\
\hline \multicolumn{15}{|c|}{ Rudder\&Propeller alone, $\mathbf{J}=\mathbf{0 . 5 1}$} \\
\hline-10 & 0 & 0.304 & 0.041 & $0.94 \mathrm{E}-3$ & 0.601 & & & 0.074 & $0.1 \mathrm{E}-2$ & -0.859 & 0.129 & & & \\
\hline 0 & 0 & 0.300 & 0.040 & $1.20 \mathrm{E}-3$ & 0.608 & & & 0.070 & 0.00 & 0.013 & 0.062 & & & \\
\hline 10 & 0 & 0.330 & 0.041 & $3.20 \mathrm{E}-3$ & 0.667 & & & 0.100 & $0.1 \mathrm{E}-2$ & 0.796 & 0.138 & & & \\
\hline \multicolumn{15}{|c|}{ Rudder\&Propeller alone, $\mathrm{J}=\mathbf{0 . 9 4}$} \\
\hline-10 & 0 & 0.060 & 0.022 & $4.30 \mathrm{E}-3$ & 0.408 & & & -0.014 & $0.2 \mathrm{E}-2$ & -0.500 & 0.074 & & & \\
\hline 0 & 0 & 0.111 & 0.022 & $0.80 \mathrm{E}-3$ & 0.754 & & & 0.037 & $0.2 \mathrm{E}-2$ & -0.040 & 0.030 & & & \\
\hline 10 & 0 & 0.116 & 0.022 & $4.30 \mathrm{E}-3$ & 0.788 & & & 0.042 & $0.2 \mathrm{E}-2$ & 0.500 & 0.070 & & & \\
\hline \multicolumn{15}{|c|}{ Rudder\&Propeller alone, $\mathrm{J}=\mathbf{0 . 3 6}$} \\
\hline-10 & -7.5 & 0.335 & 0.054 & $2.73 \mathrm{E}-3$ & 0.355 & & & 0.049 & 0.01 & -2.010 & 0.400 & & & \\
\hline-5 & -7.5 & 0.333 & 0.053 & & 0.359 & & & 0.047 & $0.90 \mathrm{E}-2$ & -1.400 & 0.130 & & & \\
\hline 0 & -7.5 & 0.332 & 0.053 & $4.88 \mathrm{E}-3$ & 0.358 & & & 0.046 & $0.90 \mathrm{E}-2$ & -0.680 & 0.059 & & & \\
\hline 5 & -7.5 & 0.331 & 0.053 & & 0.357 & & & 0.045 & $0.90 \mathrm{E}-2$ & -0.020 & 0.100 & & & \\
\hline 10 & -7.5 & 0.333 & 0.053 & $6.85 \mathrm{E}-3$ & 0.359 & & & 0.047 & $0.90 \mathrm{E}-2$ & 0.777 & 0.170 & & & \\
\hline \multicolumn{15}{|c|}{ Rudder\&Propeller alone, $\mathbf{J}=\mathbf{0 . 5 1}$} \\
\hline-10 & -7.5 & 0.303 & 0.042 & $4.70 \mathrm{E}-3$ & 0.585 & & & 0.073 & $0.2 \mathrm{E}-2$ & -1.200 & 0.190 & & & \\
\hline 0 & -7.5 & 0.302 & 0.042 & $8.10 \mathrm{E}-3$ & 0.583 & & & 0.072 & $0.2 \mathrm{E}-2$ & -0.320 & 0.022 & & & \\
\hline 10 & -7.5 & 0.300 & 0.040 & $10.40 \mathrm{E}-3$ & 0.608 & & & 0.070 & 0.00 & 0.700 & 0.085 & & & \\
\hline \multicolumn{15}{|c|}{ Rudder\&Propeller alone, $\mathrm{J}=\mathbf{0 . 9 4}$} \\
\hline-10 & -7.5 & 0.146 & 0.031 & $11.70 \mathrm{E}-3$ & 0.704 & & & 0.072 & 0.011 & -0.800 & 0.203 & & & \\
\hline 0 & -7.5 & 0.147 & 0.030 & $7.50 \mathrm{E}-3$ & 0.733 & & & 0.073 & 0.010 & -0.200 & 0.010 & & & \\
\hline 10 & -7.5 & 0.148 & 0.030 & $21.70 \mathrm{E}-3$ & 0.738 & & & 0.074 & 0.010 & 0.400 & 0.060 & & & \\
\hline \multicolumn{15}{|c|}{ Shortboard, J=0.36 } \\
\hline-10 & -7.5 & 0.315 & 0.051 & $0.53 \mathrm{E}-3$ & 0.353 & $9.71 \mathrm{E}-3$ & 0.217 & 0.029 & $0.70 \mathrm{E}-2$ & -1.920 & 0.200 & 1.542 & 21.155 & \\
\hline 0 & -7.5 & 0.313 & 0.051 & $2.52 \mathrm{E}-3$ & 0.351 & $9.77 \mathrm{E}-3$ & 0.205 & 0.028 & $0.70 \mathrm{E}-2$ & -0.710 & 0.010 & 1.542 & 21.155 & \\
\hline 10 & -7.5 & 0.313 & 0.051 & $4.12 \mathrm{E}-3$ & 0.351 & $9.77 \mathrm{E}-3$ & 0.205 & 0.028 & $0.70 \mathrm{E}-2$ & -0.500 & 0.090 & 1.542 & 21.155 & \\
\hline \multicolumn{15}{|c|}{ Mediumboard, $\mathbf{J}=\mathbf{0 . 3 6}$} \\
\hline-10 & -7.5 & 0.330 & 0.051 & $1.55 \mathrm{E}-3$ & 0.370 & 0.022 & 0.259 & 0.044 & $0.70 \mathrm{E}-2$ & -1.700 & 0.250 & 3.427 & 26.382 & \\
\hline 0 & -7.5 & 0.320 & 0.051 & $2.13 \mathrm{E}-3$ & 0.359 & 0.021 & 0.240 & 0.034 & $0.70 \mathrm{E}-2$ & -0.510 & 0.012 & 3.427 & 26.382 & \\
\hline 10 & -7.5 & 0.315 & 0.051 & $3.80 \mathrm{E}-3$ & 0.353 & 0.022 & 0.217 & 0.029 & $0.70 \mathrm{E}-2$ & 0.607 & 0.100 & 3.427 & 26.382 & \\
\hline \multicolumn{15}{|c|}{ Longboard, $\mathrm{J}=\mathbf{0 . 3 6}$} \\
\hline-10 & -7.5 & 0.321 & 0.052 & $0.15 \mathrm{E}-3$ & 0.353 & 0.016 & 0.244 & 0.035 & $0.80 \mathrm{E}-2$ & -1.754 & 0.334 & 2.534 & 32.634 & \\
\hline 0 & -7.5 & 0.318 & 0.051 & $2.10 \mathrm{E}-3$ & 0.357 & 0.016 & 0.232 & 0.032 & $0.70 \mathrm{E}-2$ & -0.600 & 0.019 & 2.534 & 32.634 & \\
\hline 10 & -7.5 & 0.314 & 0.051 & $3.70 \mathrm{E}-3$ & 0.352 & 0.016 & 0.211 & 0.028 & $0.70 \mathrm{E}-2$ & -0.600 & 0.100 & 2.534 & 32.634 & \\
\hline
\end{tabular}

Table 9: Data for all considered case 
